\title{
El cuento de los hijos ingratos y del fingido tesoro (Aa-Th. 982): raíces mí- ticas, tradiciones folklóricas y contextos culturales
}

1) En El Buen Aviso y Portacuentos de J. Timoneda se puede leer una anécdota que, como muchos de los relatos de dicha colección, se parece a un cuentecillo oral:

Estando un honrado viejo muy congojado y aflicto porque su hijo y nuera le trataban mal después que les había hecho donación de lo que tenía, le vino a consolar otro viejo, su compadre, muy sagaz, diciendo: - ¿Queréis que os sirvan y honren como de primero? Tomad una cajuela que tengo en mi posada, compadre, y henchidla de arena, y diréis a vuestro hijo que son ciertos dineros que os han restituido en ella; y vos de noche tomaréis de estas castellanas de latón y contaréis con ellas, haciendo ruido, de modo que os puedan sentir estando en vuestra cámara encerrado. Dicho y hecho. En sentir que el viejo tenía dineros, el hijo y la nuera le hacían mil caricias y fiestas, y le servían y honraban, poniéndole a cabecera de mesa. En fin, siendo muerto el buen viejo, no hallaron en la cajuela sino arena, y esta copla fijada en ella: «Por el bulto, peso y son / que de ti, arca, ha salido, / fui honrado y mantenido / y vuelto en mi posesión” 1 .

Por su contenido burlón e ingenioso el cuento tiene sabor folklórico; pero, al mismo tiempo, es relato de escarmiento $y$, por lo tanto, se asemeja a un exemplum. De hecho se encuentra otra versión del mismo tipo narrativo en el Libro de los Exemplos de C. Sánchez de Vercial, en el que se ilustra el dicho "Quien da todo lo suyo antes de su muerte / meresçe que le den con un maço en la fruente» con la narración de lo que le sucedió a un tal «Johan Ganança», adinerado burgués que había casado a sus dos hijas con dos caballeros nobles de la ciudad, a los que tanto amaba que les dio todos sus bienes. Cuando queda pobre sus yernos e hijas empiezan a mostrarse desagradecidos. Pero el anciano consigue salir del paso poniendo en obra una treta idéntica a la que

1 J. Timoneda, El Buen Aviso y Portacuentos, I, n. 26, Revue Hispanique. 24 (1911), p. 195. Lo reproduce M. Chevalier, Cuentos folklóricos españoles del siglo de Oro (Barcelona, 1983), p. 135, n." 79, «El arca de arena». 
cuenta Timoneda: se hace prestar diez mil libras por un amigo y, «un día de gran fiesta», convida a sus hijas y yernos, arreglándoselas para que, "por algunas aberturas de la puerta» de su habitación, tengan éstos ocasión de verie remover el dinero después de haberlo extraído de un arca con tres cerraduras. Cuando le preguntan de qué se trata, contesta "con engaño que eran veinticinco mil libras que tenía en guarda para hacer su testamento y dejarlas a las hijas y a sus yernos si bien se hubiesen con él y con sus hijas». Esta revelación provoca un cambio total de actitud: «... desde allí hiziéronle muchas honras en vestir y en comer y en todas las otras cosas se trabajaron de lo servir en toda su vida». Al morir, el anciano dice a sus hijas y yernos que les deja como herencia el contenido del arca; se hace entregar por ellos algún dinero, diciéndoles que sus llaves están en manos de los frailes predicadores y menores, y consigue que le entierren "con solemnes obsequias y honras». Cuando los herederos recuperan las llaves del arca confiadas a los frailes, la abren para hacerse con el dinero esperado, pero no encuentran nada más que «una maza muy grande» con una inscripción: «Yo Juan Gananza hago este testamento que cualquier que menosprecia a si por dar lo suyo a otro como hizo Juan Gananza, que en la frente le den con esta maza» ${ }^{2}$.

2) Es imposible averiguar si este cuento tenía o no vigencia oral a fines de la Edad Media y en el Siglo de Oro, aunque su presencia en un libro inspirado en colecciones de exempla nos hace sospechar que lo usaron probablemente predicadores y catequistas. Lo que sí es cierto es que el tipo narrativo que representa ha pervivido en la tradición folklórica de España hasta nuestro siglo, ya que se han recogido diferentes versiones orales en distintas partes de la Península (Asturias, Galicia, Cataluña, Portugal) ${ }^{3}$, siendo además atestiguada por una versión mejicana su implantación en Hispanoamérica ${ }^{4}$.

2 J. E. Keller (ed.), Libro de los Exemplos por A.B.C. (Madrid, 1961), pp. 111112, n." 126 (55), "Donans omnia ante mortem cum clava percuciatur in frontem». La versión rimada que figura en el Cancionero de Sebastián de Horozco (ed. de la Sociedad de Bibliófilos Andaluces, Sevilla, 1874, pp. 237-238, «A quien da lo suyo antes de su muerte le den con una porra en la frente») parece ser una adaptación versificada del cuento del Libro de los Exemplos, que depende directamente del Ludus Scacchorum (III, 8) de Jacques de Cessoles.

3 R. S. BoGGS, Index of Spanish folktales (Helsinki, 1930), FFC 90, pp. 116-117 (tipo $980 \mathrm{~A}$ ), menciona tan sólo una versión asturiana: C. CABAL, Los cuentos tradicionales asturianos (Madrid, 1924), pp. 218-220 y se refiere equivocadamente a uno de los kexemplos» de la colección de Sánchez de Vercial que corresponde en realidad a otro tipo 
Sabemos además que, como «cuento-tipo», tiene difusión internacional (se han registrado decenas de versiones, tanto en Europa como en Asia) ${ }^{5}$ y que existen versiones antiguas en latín y en lenguas vulgares, algunas en forma de exemplum ${ }^{6}$, otras en forma de novela breve o de cuento jocoso ${ }^{7}$. Las adaptaciones literarias, en particular las italianas del

narrativo. Ver, entre otras versiones catalanas, J. AMADES, Folklore de Catalunya. Rondallística (Barcelona, '1982), p. 1116, n." 490 (a propósito del dicho "Al qui sigui boig com En Rabassa, que li piquin el cap amb una maça», que parece proceder de una tradición idéntica a la que representa el Libro de los Exemplos), y la versión gallega publicada por V. Risco, en Otero Pedrayo (ed.), Historia de Galiza (Madrid, 1979), I, p. 578 (no la menciona M. Chevalier en su bibliografía), así como los dos cuentos portugueses reproducidos por T. BRAGA, Contos tradicionaes do povo portuguez (Porto, 1883), 2, pp. 134-137, n." 175, "A ingratidão dos filhos» (ambos proceden de fuentes eclesiásticas escritas. El segundo es plagio del Libro de los Exemplos, pero el primero tiene originalidad por ser protagonista principal una mujer). J. Camarena me comunica una interesante versión oral recogida por él en 1980 en la provincia de Ciudad Real.

4 H. T. WHEELER, Tales from Jalisco, México (Memoirs of the American Folk-Lore Society, 35, 1943), pp. 70-71, n." 31, «Los hermanos malos».

5 Se trata del tipo 982 de la nomenclatura folklórica de A. AARne y S. Thompson, The types of the folktale (Helsinki, '1973, FFC 184), p. 345 ( Supposed chest of gold induces children to care for aged father"); motivo P. 236-2 del Motif-index de S. Thompson. Se citan versiones italianas, germánicas, flamencas, hindúes, etc. Se puede precisar el perfil del subtipo románico comparando las versiones españolas con la siciliana recogida por G. PITRÉ, Fiabe e leggende popolari siciliane (Palermo, 1888), p. 286 y ss., n." 70, «Lu patri chi fici tistamentu» (la inscripción que acompaña la mazza dice: "Cu'pi figghi e pi nori s'ammazza / Cei sia datu'n testa cu sta mazza!»). El motivo de la maza parece ser propio de las versiones occidentales.

6 Elementos bibliográficos sobre las distintas versiones se encuentran en J. KRZYZANOWSKI, Paralele (Varsovia, 1961), pp. $51-75$ (en polaco: ver bibliografía cronológica en pp. 72-73), H. SCHWARZBaum, Studies in Jewish and World Folklore (Berlin, 1968), p. 236, n." 276, donde se estudia en especial la importante difusión del tipo en el mundo judío, y las ediciones de J. Pauli, Schimpf und Ernst por H. Oesterley (1866) (reed. en 1967) y por J. BolTE (1924), cap. 435. Para los exempla, ver F. C. TUBACH, Index Exemplorum (Helsinki, 1969, FFC 204), n." 965, p. 78 ("Chest full of stones»). El cuento figura en las colecciones de J. Gobius (Scala Coeli), J. DE BROMYARd (Summa Praedicantium I, 21, 6: ver T. WRIGTH, A selection of latin stories, Londres, 1842, n." XXVI, pp. 28-29), J. Herolt (Promptuarium Exemplorum). Ver también J. A. HeRberT, Catalogue of romances in the dept. of mss. in the British Museum (Londres, 1910), $t$. 3, que cita una versión italiana del s. Xv y otra inglesa del s. XIII (p. 653, n." 74 y p. 486, ก." 89).

7 Ver J. Dunlop, History of prose fiction (Londres, '1888), 2, p. 185 y ss. (Brevio, Sercambi, Cademosto da Lodi, etc...). También se puede consultar D. P. Rotunda, Motifindex of the italian Novella in prose (Bloomington, 1942) (motivo P, 236-2), P. RAjNA, «Una versione rimata dei Sette Savi», Romania, 10 (1881), pp. 9-11, «Il forziere»; F. H. VON DER HAGEN, Gesammtabenteuer (Stuttgart-Tübingen, 1850), t. 2, pp. LVIII-LXVI (a propósito de Der Schlägel, de Rüdiger de Hunthover, reproducido por el mismo V. 
Renacimiento, parecen dimanar más o menos directamente de los exempla latinos medievales, pero éstos, a su vez, se concluyen, en algunas ocasiones, con un dicho formulado en lengua vulgar. Así que resulta difícil determinar el supuesto «origen», culto o folklórico, del cuento: desde las versiones más antiguas se manifiesta un probable intercambio entre formas "populares» y clericales ${ }^{8}$.

Cabe notar, por otra parte, que si el cuento tiene, en sus versiones más antiguas, forma de exemplum, su contenido no resulta en absoluto religioso o edificante: la evocación del tema de la ingratitud no desemboca aquí en ninguna incitación a la reforma moral sino tan sólo en un consejo de carácter puramente práctico y admonitorio ${ }^{9}$. Es cuento de escarmiento, que concluye con una llamada a la prudencia financiera más elemental: refleja por lo tanto una mentalidad «burguesa», pragmática, y el tono algo burlón de la moraleja tiene resabios socarrones y desengañados.

En realidad, el relato es esencialmente ilustración relativa de un dicho que se fija textualmente en la inscripción final: la versión del Libro de los Exemplos es, sobre este particular, mucho más conforme que la de Timoneda (que ameniza torpemente la conclusión) a la tradición europea general, en la que el mensaje escrito dejado por el anciano suele aludir a un objeto - mazo, cachiporra o martillo- depositado en el arca, sien-

der Hagen, ibid. pp. 401-451, n." 49). Varias versiones más, literarias y folklóricas, son reseñadas. por R. Köhler, Kleinere Schriften (Weimar, 1898-1900), t. 1, p. 431 y t. 2, p. 558. Las relaciones entre versiones españolas e italianas antiguas se traslucen en la onomástica: "En Rabassa» en la versión catalana de Amades, "Juan Gananza», en el Libro de los Exemplos y Juan Cabaca en el Cancionero de Horozco, parecen recordar a "Giovanni Gavazza» (ver F. Zambrinl, Libro de novelle antiche, Bologna, 1868, n." 10, "Testamento di Giovanni Gavazza"): en varias versiones antiguas el protagonista se llama Conaxa.

8 La versión latina de J. Gobius da en francés el texto de la inscripción que va en el mazo: «De quest marcel sy'ensucat / Qui per suos enfans s'est deseretat». En la versión alemana de Pauli se indica que los versos son ingleses; lo mismo pasa al final de la versión latina de Wright, que cita dichos versos en su idioma original, añadiendo a continuación la cuarteta francesa de la que son traducción literal ( De un tiel mael seit-it feru, / Ke seit par mi le monde conu, / Ky doune kaunke il a à soen enfant, / E va ly meimes mendiaunt»). P. Rajna deduce de ello que la versión de Gobius "va ricondotta, direttamente o indirettamente, a una redazione provenzale smarrita», y que la de Pauli depende probablemente de un texto latino que es, "quasi di sicuro», traducción de un original francés (op. cit., p. 11).

9 La única moraleja que, muy inadecuadamente, consigue J. Bromyard sacar de este exemplum es: «Ex isto patet, quod solus pauper scit quis ejus sit amicus» (Summa Praedicantium, ed. de Venecia, 1586, t. I, p. 55). Es lugar común, nada edificante, que puede aplicarse a muchísimos cuentos y se encuentra en multitud de colecciones orientales. 
do dicho instrumento como el jeroglífico en el que se concretiza la «ejemplaridad» de toda la narración. El comentario métrico que acompaña el objeto tiene sin duda existencia independiente ${ }^{10}$ : su formulación en lengua vulgar y el hecho de que se encuentre, en forma bastante parecida, en muchas versiones y en varios países, parecen demostrar que dichas versiones se remontan más o menos directamente a un original común en romance. Además, resulta obvio que el relato se ha construido a partir de este elemento formulístico, perteneciendo, por lo tanto, a la categoría de los cuentos en forma de glosa paremiológica: por una parte se ha objetivado el dicho popular anejándolo a la realidad concreta de la maza puesta en escena, que de instrumento imaginario viene a ser evidencia material y simbólica a la vez; por otra parte, se ha montado una estructura narrativa que permita la articulación de este conjunto significante dicho-objeto con un motivo cuentístico (la burla del supuesto tesoro que resulta ser un arca vacía o de contenido irrisorio). A la par que se le confiere fuerza y aplicabilidad al dicho general y alusivo por la movilización efectiva del objeto aludido, se da por la narración un ejemplo particular de situación concreta en la que se demuestra la eficacia del precepto que entraña la alusión.

Así que el cuento estriba en un registro doble: el mensaje es visual e intelectual, burlón y admonitorio, sobreponiéndose la broma y la advertencia, concretadas en el mismo y único motivo ${ }^{11}$. Se funden en el mismo objeto el castigo metafórico a los eventuales padres imprudentes y el castigo real a los hijos ingratos presentes ${ }^{12}$. Tal tipo de ambiva-

10 J. AmADES, op. cit., p. 803, apunta que el mensaje corresponde a un refrán que se suele usar, fuera de todo contexto narrativo, y en formulaciones más o menos estables, en toda la parte mediterránea de España (en Valencia: "Al qui donació faça, que li xáfon lo cap amb una maça»; en Mallorca: "Qui de fer donació en vida es propassa, que li batin es cap amb una maça», etc.).

11 En algunas versiones el sentido se empobrece y sólo se retiene la burla a los herederos. En una versión turca el arca no contiene más que excrementos: G. DUMÉzIL, Documents anatoliens (Paris, 1967), IV, Pp. 117-119, n." 20, "Les héritiers bernés», o se refuerza el carácter chistoso y escarnecedor de la conclusión al sustituir a la cachiporra por un cuerno que los padres imprudentes son invitados a hincarse en el culo... (ibid. loc. cit).

12 Otra vez algunas versiones eliminan la ambigüedad final al especificar que el mensaje (y la maza) van dirigidos únicamente a los herederos burlados (cf. el texto recogido por P. RAjNA, op. cit., p. 10, en el que la inscripción reza: «Chi questa maza averá a trovare / Con esa instesa se deza discopare»). En la versión de Ciudad Real recogida por J. Camarena la conclusión es más compleja: «Aquí lo que dejo son unas piedras para la avaricia de mis nueras, que crean que es oro; pero lo que sí dejo es una garrota a mis hijos, para que, si reparten lo suyo antes de la muerte, les peguen 
lencia semántica y el simbolismo concreto, gráfico, del motivo final son rasgos específicos del cuento popular, oral y folklórico, reacio a las moralizaciones abstractas y unívocas que caracterizan las ficciones clericales o eruditas.

Este tenor tradicional se confirma por el examen de los componentes del tipo narrativo al que corresponden los cuentos que estudiamos: vamos a ver que se sitúa este tipo en la encrucijada de varias tradiciones literarias de fuerte entronque folklórico.

3) En primer lugar, nuestro relato se nos aparece como un desarrollo original del conocido tema del fingido tesoro o de las arcas de arena. En este tema se fundamenta un cuento que parece ser de origen oriental y se difundió por Europa a través de la Disciplina clericalis de Pedro Alfonso y los Gesta romanorum. Se volverá a encontrar hasta en el Decamerón, el Libro de los Exemplos y otras muchas colecciones en lengua vulgar, así como en versiones orales folklóricas ${ }^{13}$.

unos buenos garrotazos mis nietos a ellos, porque es lo que tenían que haber hecho conmigo para no haberlo repartido, porque no se debe dar lo que tiene cada uno hasta que no se muera» (cf. la versión mejicana de Wheeler).

13 Tipo Aa-Th. 1617 («Unjust banker deceived into delivering deposits...») motivo K. 1667. Ver E. Hermes, The Disciplina Clericalis of Petrus Alphonsi (trad. ingl., Londres, 1977), pp. 128-130 (n." 15) y notas p. 185. Es n." 118 de Gesta Romanorum (ed. H. Oesterley). VIII-10 del Decamerón, y 163(92) del Libro de los Exemplos (ed. cit., pp. 135 y ss.). Se indican las versiones y paralelos orientales en N. M. Penzer (ed.): The ocean of story (Londres, 1925), t. 3, pp. 118-119, V. CHAUviN, Bibliographie des ouvrages arabes (Liège-Leipzig, 1905), t. 9, pp. 23-24, n." 13. La tradición europea es estudiada por A. C. LEE, The Decameron, its sources and analogues (Londres, 1909), p. 266 y ss. y L. di Francia, "Alcune novelle del Decameron illustrate nelle fonti», Giomale Storico della letteratura italiana, 44 (1904), pp. 70-80, que menciona la relación de este tipo con el 982. R. S. BogGS, op. cit., p. 135, cita una versión oral asturiana. Cabe notar que el motivo de las arcas llenas de arena o de piedras no aparece en todas las versiones (aunque sí en la Disciplina Clericalis y en los textos que dependen de ella) ya que frecuentemente sólo se trata de un hombre (generalmente un ciego) que consigue recuperar el dinero enterrado que se le ha robado, haciéndole creer al ladrón que va a enterrar más en el mismo lugar. El tipo 1617 es estudiado por H. ScHWARzBAUM, op. cit., pp. 239-240, n." 281 (ver también su estudio sobre el cuento n." 15 de la Disciplina Clericalis en Sefarad, 22, 1962, pp. 31-32) y sobre todo por L. MONTGOMERY, "Confided property», Romanic Review, 18 (1927), pp. 22-36. Hay versión española antigua en TIMONEDA (El sobremesa $y$ alivio de caminantes, II, 59, B.A.E., 3, p. 181, «Nunca más perro al molino») que adopta el subtipo del ciego y del ladrón, y versión dramática por LOPE DE VEGA en El anzuelo de Fenisa. La versión presentada por Narciso CAMPILlo, Una docena de cuentos (Madrid, 1875), "La hacha del ciego", recuerda el tipo 982 por el último motivo: en el lugar del esperado tesoro el ladrón sólo encuentra una cuerda con un nudo. 
Aquí no se trata de herederos ingratos, sino de un banquero deshonesto, que se niega a devolver el dinero que se le ha dejado en depósito. Se le induce a la restitución por un ardid ingenioso: le muestran algunas arcas supuestamente llenas de oro -en realidad repletas de piedras- haciéndole creer que van a ser objeto de otro depósito. Para acreditar su fiabilidad y llevarse el «tesoro», el alevoso banquero se apresura a devolver el primer depósito, resultando engañado por su propia avidez e insuficiente astucia.

El supuesto tesoro desempeña el mismo papel que en el cuento en que se centra este estudio, ya que sirve para suscitar la codicia de una persona y obtener de ella que cumpla un compromiso que quiere olvidar, haciéndole esperar, mediante un engaño, que podrá lograr beneficios aún más importantes que los que sus previas artimañas le habían permitido granjearse.

La relación entre ambos tipos narrativos es manifiesta en las versiones del cuento de los herederos ingratos en las que el padre pide a sus hijos - como lo hace en el Libro de los Exemplos- que le devuelvan algún dinero cuando ya está a punto de morir ${ }^{14}$.

Este tipo de cuento se subdivide en dos subtipos: en el primero, al que corresponde el esquema que acabo de resumir, se trata de recuperar el dinero dejado en depósito; en el segundo, representado por muchas versiones orientales, el héroe consigue que el ladrón que le ha robado el dinero que había ocultado en algún escondite lo vuelva a colocar en su sitio al esperar recoger más.

El motivo de las arcas de arena se usa únicamente en el primer subtipo, al que corresponde, a raíz de la Disciplina Clericalis, la mayoría de las versiones occidentales. Aunque figura en algunas versiones árabes, es sobre todo característico de las versiones europeas, e incluso nos podemos preguntar si no es un motivo esencialmente español: en efecto, en el relato de Pedro Alfonso, del que arrancan, directa o indirectamente,

14 «E estando allí en la cama, demandó a los yernos que le diesen cierta cuantía de dineros, lo cual ellos hicieron luego de buena voluntad esperando, lo que habían de heredar del testamento que esperaban en breve». No se entiende muy bien para qué va a servir este dinero, a no ser que el anciano lo ponga en reserva para una donación piadosa o para costear su propio funeral. El episodio parece ser superfluo y sólo se explica como reminiscencia o contaminación del tipo 1617. También se puede notar que el papel desempeñado por el «amigo del héroe», al darle el buen consejo que le permitirá salir de apuro (tipo 982) ya es una característica del tipo 1617: en varios cuentos orientales, relacionados con el mismo tema del ardid destinado a recoger dinero dejado en depósito y confundir al banquero deshonesto (cf. Chauvin, loc. cit.). es el cadí o un amigo astuto el que encuentra la solución y salva al protagonista. 
todas las versiones occidentales, se indica que el protagonista es un español musulmán; por otra parte, sabemos, por las Partidas, que el engaño de los «sacos e bolsas e arcas cerradas llenas de arena e piedras» para «hacer entender que es tesoro» debía de practicarse en España, ya que «algunos homes $[\ldots]$ con este engaño toman dineros prestados» ${ }^{15}$; y queda, por fin, sobradamente conocido el episodio del Cantar de Mio Cid en el que el héroe castellano consigue dinero de los judíos Raquel y Vidas entregándoles dos arcas llenas de arena ${ }^{16}$.

En este último caso no se trata de recuperar dinero robado, dejado en depósito a un banquero de mala fe o imprudentemente legado a herederos ingratos, sino de obtener crédito con un engaño que la ulterior devolución del préstamo volverá inocente ${ }^{17}$. Pero varios detalles muestran que estas tradiciones son solidarias, ya que van intercambiando sus elementos: el citado relato de Timoneda se aleja por ejemplo del tipo narrativo del que depende al no hacer uso del motivo final de la maza, que se encuentra en la mayoría de las versiones occidentales, y al sustituir a este motivo por el del arca de arena, manifiesto recuerdo del cuento del banquero de mala fe o del engaño cidiano ${ }^{18}$. También son comunes a la tradición épica y a los cuentos folklóricos el engaño subsidiario, denunciado por las Partidas, de mostrar un poco de oro para hacer creer que hay mucho más ${ }^{19}$, y la circunstancia del convite desti-

15 Partidas VII. 16.9 ( Engañadores hay algunos homes de manera que quieren facer muestra a los homes que han algo, et toman sacos e bolsas e arcas cerradas, llenas de arena o piedras, o de otra cosa cualquier semejante, e ponen desuso, para facer muestra, dineros de oro o de plata o de otra moneda, et encomiéndanlas et danlas a guardar en la sacristanía de alguna eglesia o en casa de algunt home bueno, faciéndoles entender que es tesoro aquello que les dan en condesijo, et con este engaño toman dineros prestados": citado por R. Menéndez Pidal en su edición breve del Poema de Mio Cid, Madrid, 1913, pp. 33 y ss.).

16 Ver R. M. PIDAL, op. cit., loc. cit.. donde se mencionan paralelos clásicos, algunas versiones del tipo 1617 y el cuento 26 del Portacuentos de Timoneda.

17 Cf. motivo K 455-9 ("Worthless chests offered to obtain credit»), a propósito del cual S. Thompson cita sólo un cuento italiano (P. Fortini), quedando olvidado el ejemplo mucho más famoso del cantar español.

18 Notemos también que el detalle de los tres cerrojos que se encuentra en Exemplos $126(55)$ ("un arca nueva con tres cerraduras») es palmario eco del episodio de Raquel y Vidas tal como lo cuenta la Crónica del Cid (donde se especifica que los dos cofres van «con cada tres cerraduras»): cf. G. Cirot, "L'affaire des malles du Cid», Bulletin Hispanique. 48 (1946). En varias versiones del tipo 1617 se insiste, como en el episodio cidiano, en el adorno y las cerraduras del cofre (cf. Exemplos 163(92): «... diez cofres muy pintados de fuera e ferrados con planchas argenteas e con buenos ferrojos...»).

19 Este motivo, ya presente en Herodoto (III, 123), parece ser trasposición de una 
nado a adormecer la posible desconfianza del protagonista al que se va a engañar 20 .

Estas transferencias se podrían explicar por reminiscencias literarias, pero es más probable que haya intervenido un importante factor de tradición oral: sabemos, por ejemplo, que el episodio de las arcas de arena se solía contar, hasta épocas bastante recientes, como leyenda explicativa relativa al cofre antiguo colgado de uno de los muros de la Catedral de Burgos ${ }^{21}$. Además, la práctica efectiva del timo de las arcas de arena, atestiguado por Las Partidas, le daba un trasfondo social suficiente al tema folklórico para mantenerlo vivo en la conciencia y memoria colectivas.

4) Sin embargo, la tradición relativa al engaño del arca de arena se entronca, en el tipo narrativo que examinamos aquí, con otra tradición folklórica acaso más antigua y amplia: la de las ficciones admonitorias destinadas a exponer el peligro de las donaciones.

4.1. Al parecer, esta tradición se enraíza en un viejo tema indoeuropeo, que puede rastrearse hasta el tipo mítico del rey de los primeros tiempos, que, al envejecer, comete un pecado o un error fatal y se despoja de las posesiones que dan realidad y fuerza concreta a su soberanía repartiendo entre sus hijos las distintas partes de su reino.

práctica efectiva (cf. supra n. 15); en la Crónica del Cid, como lo recuerda R. M. PIDAL (op. cit.), se oculta la arena de los cofres con una capa superficial de oro y piedras preciosas. Del mismo modo, en muchas versiones del tipo 982 el anciano se hace prestar por su amigo algunas monedas y las usa ostensiblemente para acreditar la idea de que tiene todo un tesoro oculto en reserva. En el tipo 1617 también se recurre -o aludea veces a una pequeña cantidad de dinero para inspirar confianza en las engañosas arcas. En algunas versiones del tipo 982 (cf. J. Camarena y la versión francesa medieval mencionada abajo, n. 43) aparece un motivo que recuerda un conocido episodio de la historia de Ali-Babá: el anciano deja una moneda de oro en el fondo del celemín que se hace prestar por una de sus nueras y ésta cree que usó dicho instrumento para medir una cantidad importante de dinero.

20 En el romancero del Cid el contrato entre el héroe burgalés y los judíos se hace cuando éstos son invitados por aquél: «A dos judíos convida / $\mathrm{Y}$ sentados a su mesa / Con amigables caricias / Mil florines les pidiera» (cf. G. Cirot, op, cit.). Recordemos que en Exemplos 126(55) el anciano «un día de gran fiesta convidó a los yernos e a las hijas». Al revés, en una versión oriental del tipo 1617, es el ladrón el que invita al protagonista, que acaba de hacerle creer que va a poner más dinero en el escondite, a fin de darse tiempo para volver a poner en su sitio lo que ha robado anteriormente: R. F. BuRTON, Supplemental Nights (Benares, 1886), t. 1, pp. 264-266, "The tale of the melancholist and the sharper".

21 Cf. G. CIROT, op. cit. 
Esta repartición, versión política de un acto cosmogónico y primordial, desencadena un proceso que cobra dimensiones y significaciones diversas en los casos del rey indio Yayāti (en el Mababharata) o del conde francés Aymeri (en la gesta medieval de los Narboneses) ${ }^{22}$ : pero es en la leyenda del rey Lear, tal como, la cuenta Geoffrey de Monmouth, donde más de manifiesto se pone el peligro que entraña, para el imprudente y encanecido donador, el abandonar sus posesiones y su poder contando con sus herederos para que respeten sus supuestas prerrogativas y mantengan la dignidad de su vejez ${ }^{23}$.

En el prototipo indo-europeo el desposeimiento del rey suele sancionar un(os) pecado(s) cometido(s) anteriormente por él (orgullo, injusticia, traición, irregularidad sexual): a raíz de esta transgresión inicial el monarca se ve abandonado por los distintos componentes de su soberanía y por su fuerza vital, recuperados por otros protagonistas según un esquema trifuncional ${ }^{24}$. Así que la «distribución», que concierne más las esencias de la realeza que los bienes y territorios que le corresponden, es involuntaria, espontánea ${ }^{25}$. En el caso de Yayāti, el pecado inicial, que es de carácter sexual, determina un envejecimiento repentino del rey, y la distribución del reino a sus herederos (privilegiando al hijo menor que demostró mayor abnegación que sus hermanos al aceptar regalar su propia juventud a su padre y asumir la vejez de éste) es consecuencia de los esfuerzos del soberano para remediar esta degradación personal: empresa que implica un escrutinio de la buena voluntad de cada uno de sus herederos y de sus aptitudes respectivas para asumir o no la soberanía ${ }^{26}$.

22 Cf. G. DumEzIL, Mythe et épopée (Paris, 1971), II, pp. 251-300, y J. H. Grisward), Archéologie de l'épopée médiévale (Paris, 1981), pp. 80-135. Ver también M. Defourny, Le mythe de Yayäti (Paris, 1978), passim.

23 Ver el estudio de J. H. GRISWARD (de próxima publicación en Le roi indoeuropéen) sobre la relación de la leyenda de Lear con el ciclo mítico reconstituido por Dumézil. Se puede ver también T. L. MARKEY, «The cosmology of Lear and his daughters», Mélanges G. Dumézil (Washington, 1982), pp. 133-139, que sugiere una interpretación trifuncional de las hijas de Lear; W. PERreTt, «The story of King Lear, from (ieoffrey of Monmouth to Shakespeare», Palaestra, 35 (1904), y E. FARAL, La légende urthurienne (Paris, 1929), t. 2, pp. 109-112, y t. 3, pp. 99-104.

27 Hay convergencia, sobre este punto particular, entre el tema del pecado único (trifuncional) del primer rey y la serie de los tres pecados del guerrero (que corresponden respectivamente a cada una de las tres funciones): ver G. Dumézll, Heur et malheur du guerrier (Paris, '1985), pp. 95, 105 y 107.

25 Es el caso de Yima en la mito-historia iraní (G. DumÉzIL, op. cit., pp. 292-300 y $310-315$ ).

26 Ibid., pp. 258-271. En este caso la distribución del reino equivale a un desposei- 
Como lo mostró J. Grisward, el caso de Aymeri de Narbonne se conforma al mismo esquema, con la variante de que el "pecado» no es anterior al escrutinio de los herederos: es después de haber sometido a sus hijos a una prueba discriminatoria, cuando. Aymeri les distribuye reinos todavía por conquistar. Esta repartición es acompañada por una sentencia injusta, ya que, al mismo tiempo, Aymeri expulsa a sus hijos, maldiciendo, en una versión italiana, a Aïmer, que es en realidad el que le tiene más respeto y amor ${ }^{27}$. Así que a la imprudencia que implica el expulsar a sus hijos, que son los soportes de su poder, el anciano añade un criterio equivocado e injusto.

Lo mismo pasa en la leyenda del rey Lear, en la que el obcecado monarca, al envejecer, se despoja de su poder y de su reino en beneficio de sus tres hijas y de sus yernos, desfavoreciendo sin embargo a la única de sus herederas que le tiene realmente afecto, porque ésta se negó a propinarle las lisonjas que el presumido y desatinado anciano esperaba. Se sabe cuál fue la ingratitud de las dos mayores y qué disgustos le acarreó a Lear su excesiva confianza e indiscreta partición. Como Aymeri, Lear yerra al momento de repartir. Lo mismo que Yayāti es salvado, al fin y al cabo, por su hijo menor (y, en otro episodio, por su hija) ${ }^{28}$, Lear es restaurado finalmente por la última de sus hijas. En el caso de Lear la transgresión real es doble: consiste en un pecado (la presunción y la ceguera mental que determinan un reparto injusto) ${ }^{29}$ y en un error (despojarse de su reino antes de su muerte en favor de herederos de poca confianza, y no saber discernir dónde está su verdadero apoyo) ${ }^{30}$. Como Yima y Yayāti, Lear será sancionado por su or-

miento, ya que el rey no abdica antes de tiempo (se contenta con designar por anticipado a su sucesor). Además consigue así recuperar su juventud.

27 J. H. Grisward, Archeologie..., pp. 94-105.

28 Yayāti es salvado, una primera vez, por su hijo menor, que cambia su propia juventud por la vejez de su padre, y otra vez por su hija, Mādhavī, que, en un episodio póstumo en el que se repite la secuencia pecado-decadencia-restauración, contribuye, con la ayuda de sus cuatro hijos, a restituirle su gloria celeste (G. DumEzIL, op. cit., pp. 316-330). Un paralelo céltico atestigua la preexistencia de un tipo mítico indo-europeo de entidad femenina estrechamente relacionada con la realeza (ibid., pp. 331-353).

29 El mal criterio de Lear es efecto de su excesiva presunción: favorece a los aduladores y no sabe reconocer la escueta verdad. En ello se parece a Yima, Yayāti y Aymeri, que pecan por orgullo.

30 Sobre este punto particular es más relevante la comparación con Aymeri, que comete el error de expulsar a sus hijos (que son los reales mantenedores de su potencia), desfavoreciendo precisamente a los que le tienen mayor devoción (cf. J. H. GRISWARD, op. cit., p. 105 y pp. 114-124). El caso de Yayāti es simétrico y contrario: la expulsión no es error o pecado, sino justicia, ya que sanciona atinadamente a los hijos menos 
gullo e imprudencia al verse desposeído de su reino $y$ de los símbolos de la realeza ${ }^{31}$ : el abandonar parte de su tierra a sus yernos va a implicar, de facto, una involuntaria abdicación, directamente relacionada con el envejecimiento, ya que sus yernos aprovechan su creciente debilidad para rebelarse e imponer sus condiciones ${ }^{32}$.

4.2. El cuento del fingido tesoro se inscribe claramente como rebrote menor y tardío de este conjunto de tradiciones narrativas, aunque en forma folklorizada y reinterpretada. Aquí sólo se trata de la repartición de una herencia, pero resulta evidente que la estructura es parcialmente idéntica: el error del protagonista consiste, como en el caso del rey Lear, en despojarse imprudentemente de sus bienes antes de su muerte ${ }^{33}$; el castigo es verse desposeído sin obtener a cambio de su donación las prestaciones materiales y beneficios morales que suponía el implícito contrato. La restauración radica en la recuperación parcial de dichos beneficios y prestaciones y en la consecución de una vejez desahogada y digna, aunque desengañada.

En nuestro cuento no hay escrutinio de los herederos ni repartición selectiva de los bienes, sino donación global e indiscriminada. Asimismo

adictos a la causa de su padre. El reparto del mundo es consecuencia de un pecado anterior pero no constituye de por sí un acto negativo y debilitante: cuando Yayāti le restituye su juventud a su hijo, tras mil años dedicados a los placeres de la vida, le da, al mismo tiempo, la corona, pero esta abdicación no implica ninguna disminución individual (se inicia entonces un período ascético de preparación para el puesto glorioso que le espera en el cielo después de su muerte).

31 En el caso de Yayāti, cuya soberanía terrenal no sufre ninguna alteración, esta decadencia se produce post mortem, cuando su presunción le hace caer del cielo (G. DumÉzIL, op. cit., pp. 274 ss.).

32 «Post multum vero temporis, ut Leir torpere coepit senio, insurrexerunt in illum praedicti duces, quibus Britanniam cum filiabus diviserat, abstulerunt autem ei regnum regiamque potestatem, quam usque ad illud tempus viriliter et gloriose tenuerat» (G. de Monmouth, Historia Regum Britanniae, cap. 31, en E. Faral, op. cit., p. 101). Aquí la vejez es ocasión del castigo (en la leyenda de Yayāti y sus hijos el envejecimiento era el castigo). En cuanto a Aymeri, como lo muestra muy bien J. H. GRISWARD, su «locura» consiste en no admitir su propia vejez (op. cit., pp. 116 y ss.). Así que, de un modo u otro, el "pecado» del "Primer Rey" tiene relación con la senescencia.

33 No hay pecado, sino mera tontería. Pero en algunas versiones se especifica que el anciano, que es un burgués rico, quiso casar a sus hijos (o hijas) con miembros de la nobleza (cf. Libro de los Exemplos: «... casolas con dos cavalleros nobles») y en una de las versiones portuguesas se explica la donación por el deseo de dar estado a las hijas «com mais grandeza» (T. BRAGA, op. cit., p. 135). Lo mismo pasa en las versiones medievales del tipo 980 - «Half carpet»- que pertenece, como veremos a continuación, al mismo ciclo folklórico. Esta transgresión social equivale al pecado de orgullo en el prototipo indo-europeo. 
no se encuentra rastro de diferenciación entre los beneficiados, ya que todos resultan igualmente ingratos $\mathrm{y}$, por lo tanto, descalificados. Sin embargo, el tema de la prueba discriminatoria reaparece en la segunda parte del relato: al sugerir que todavía no ha repartido la totalidad de sus bienes y que le queda un «tesoro", el anciano crea una emulación, una especie de concurso entre los herederos potenciales ${ }^{34}$. Generalmente esta competencia es implícita, pero en algunas versiones se presenta como una verdadera "prueba de los amigos», ya que el padre indica que el suplemento de herencia servirá para recompensar al que haya manifestado mayor solicitud filial ${ }^{35}$, y en contados casos va a visitar separadamente a sus hijos o yernos en sus casas para comprobar sus respectivas manifestaciones de seudo-devoción ${ }^{36}$.

Claro está que esta pretendida prueba es pura ficción, ya que el protagonista sabe a qué atenerse de antemano y está preparando la burla final: el esquema mítico se ha subvertido y adecuado a un tipo de situación más prosaico y soez. No obstante, el mecanismo de la recuperación presenta extrañas analogías con los episodios correspondientes en las formas míticas del ciclo: para el anciano se trata de reconstituir las ventajas de las que se ha privado al hacer donación de toda su hacienda a unos ingratos, y lo consigue induciendo a sus herederos a hacer la retrocesión (parcial o traspuesta en prestaciones concretas) de los bene-

34 Aquí se cruza nuestro cuento con el tema del anciano que aprovecha la codicia de los cazadores de herencias para lograr prestaciones extraordinarias y finalmente engañarlos. Se sabe que este subtema del ciclo del captator captatus tiene raíces antiguas (Luciano, Horacio, Petronio) y que lo renovó magistralmente Ben Jonson en Volpone.

35 Cf. T. BRAGA, op. cit., p. 136: el anciano finge haber conservado algún dinero para hacer testamento diciendo que legará dos mil cruzados a sus hijas, "deixando a uma ou outra mais ou menos, conforme os obsequios e serviços que d'ellas recebesse...». En la versión mejicana de WHEELER (op. cit., p. 71 ) las nueras instigan a sus maridos para que cuiden al anciano "pa que te acabe de dar la herencia». En el cuento turco recogido por G. Dumézil, el padre le promete separadamente a cada uno de sus hijos que será el único heredero ( ${ }^{2}$ 'est toi qui me traites le mieux. C'est pourquoi je le dis à toi seul»), y todos empiezan a rivalizar («... traitons le bien, puisqu'il nous a donné cet argent. Qu'il n'aille surtout pas le donner à ses autres fils, si nous le fâchons!»). Esta prueba-competición es también elemento esencial de la versión cingalesa recogida por H. PARKer, Village folk-tales of Ceylan (Londres, 1914), t. 3, n. 234, pp. 240-242, "How the daughter in law got the masuram", en la que la anciana convoca a su parentela y dice que legará su supuesto tesoro a quien se haya ocupado de ella con más devoción.

36 En varias versiones esta ronda alternativa del padre por las casas respectivas de sus hijos o yernos se instituye desde la donación inicial: es para el anciano ocasión de constatar que todos lo tratan igualmente mal (lo mismo pasa en la leyenda de Lear con sus dos hijas mayores). 
ficios recibidos; otro tanto pasa, mutatis mutandis, en la leyenda de Yayāti, en la que los nietos del rey detentan cada uno por separado una porción del total de los méritos que poseía sintéticamente Yayāti antes que su pecado de orgullo le hubiese precipitado del cielo. Será necesario reconstituir este caudal místico-moral y transferirlo al decaído soberano para que éste recupere el puesto perdido. Esta restauración implica que cada uno de los nietos ponga a disposición del abuelo su tesoro parcial, para que éste, pueda reunificar el conjunto sintético y completo por cuya virtud su decadencia va a transformarse en ascensión ${ }^{37}$.

La transferencia de los méritos y la reasociación de los componentes de la gloria soberana son operaciones místicas espontáneamente aceptadas por los nietos ( $\mathrm{y}$ aún impuestas a su real abuelo, reacio a aceptar tal limosna), mientras que, en el cuento del que nos ocupamos, la restitución o restauración conseguida por el anciano es puramente material y se logra mediante un engaño, ya que los herederos no están dispuestos para semejante acto de abnegación: el mito se ha profanizado y se han invertido los papeles y significados, ya que a la generosidad absoluta ha sustituido la más crasa ingratitud. Sigue en pie, sin embargo, la estructura ${ }^{38}$, aunque recorrida al revés (en un caso el anciano obliga, mediante una ficción, a sus herederos a que respeten colectivamente el implícito contrato; en el otro son los nietos y la hija los que apremian al rey a aceptar la reversión del capital moral del que gozan por partes separadas: en ambos relatos triunfa finalmente y a la fuerza la reciprocidad), y la operación que restituye el intercambio normal de prestaciones se lleva a cabo por medio de un ardid, medio moral, medio jurídico, que constriñe a la parte reacia a que acepte otorgar o recibir la debatida prestación ${ }^{39}$.

\footnotetext{
37 G. DumÉZIL, Mythe et épopée, t. 2, pp. 281-282.
}

38 Estructura narrativa más que ideológica, ya que la dimensión trifuncional en la leyenda de Yayāti, ha desaparecido por completo en la tradición folklórica medieval y moderna de que nos ocupamos, aunque puede considerarse acaso como reliquia de ella - desvirtuada por cierto- el motivo, que aparece en una versión, de la atribución por el anciano de tres porciones diferenciadas de dote a sus tres hijas, que reciben respectivamente 300, 200 y 100 táleres, correspondiendo luego cada una de ellas a la generosidad de su padre con un regalo distinto: una cuerda (sugestión para un suicidio), un talego de mendigo, y un pastel. J. WENZIG, Westslavischer Märchenschatz (Leipzig, 1857), p.
276 .

39 En la leyenda india, la hija de Yayãti consigue convencer a su padre a que acepte la transferencia de los méritos de sus nietos en su propia cuenta corriente metafísica, al añadir la mitad de sus propios méritos a este capital colectivo: es este suplemento, resultado de una especie de puja, el que fuerza la aceptación del rey. Del mismo modo, y 
El engaño del falso tesoro o del aparentar que se posee algo que en realidad no existe, hemos visto que probablemente procede de otros tipos de cuentos y de la larga tradición folklórica y literaria de los distintos embustes mediante los cuales uno puede obtener dinero a costa de quien lo tiene y no lo suelta sin que se estimule su codicia de tener más, tradición tanto más arraigada cuanto que corresponde a prácticas económicas efectivas corrientes en sociedades precapitalistas. Pero, considerándolo bien, este tipo de bluff se encuentra también, independientemente de todo contexto monetario, por lo menos en una de las leyendas del ciclo indo-europeo de narraciones y representaciones en el que se enraíza el cuento que se estudia aquí: hay que notar, en efecto, que Lear consigue recuperar su soberanía gracias a la ayuda del rey de Francia, Aganipo, esposo de su hija mayor, Cordeilla, y que logra esta asistencia gracias a una ficción análoga a la que usa el anciano de nuestro cuento (como se lo había aconsejado Cordeilla, Lear se presenta ante Aganipo con una comitiva de lujo, fingiendo tener todavía la posibilidad de mantener su rango y ocultando la realidad de su miseria gracias al dinero que le da o presta secretamente Cordeilla) ${ }^{40}$. En ambos casos, aunque por vías diversas, uno recupera lo que ha perdido gracias a la ficción de que todavía le queda algo. En ambos casos también se necesita el concurso de un auxiliar astuto y generoso, que idea la estratagema y presta el dinero necesario para mantener la ficción: en el cuento es un amigo fiel quien le sugiere el engaño al anciano y le entrega las monedas necesarias para ponerlo en obra ${ }^{41}$.

4.3. Resulta, por lo tanto, que en la Edad Media el ciclo mítico relativo a las vicisitudes del Primer Rey (pecado, castigo, redención) suministró sus temas, motivos y estructuras narrativas a un conjunto de

al revés, en el cuento, es la esperanza de obtener un suplemento de herencia el que mueve a los hijos ingratos a propinarle finalmente al anciano las ventajas que él quiere obtener a cambio de la donación.

40 Así que puede presentarse ante el rey franco como su igual.y obtener su respeto y ayuda contra los usurpadores: este momento es objeto de toda una mise en scène cuidadosamente preparada por Cordeilla, que exige que su padre aparezca regio apparatu ex ornamentis et familia insignitus (E. FARAL, op. cit., p. 104).

41 Hemos visto que este auxiliar, en el mitologema indo-europeo, es generalmente uno de los hijos (o hijas) del anciano rey, que no comparte la ingratitud de sus hermanos o hermanas y toma el partido del padre contra ellos. En el cuento todos los herederos son ingratos, ya que se trata de exponer el peligro de las donaciones en general: por eso el papel del auxiliar es desempeñado por algún amigo fiel (lo mismo pasa en muchas versiones del tipo 1617). 
relatos fundados en la idea de la donación imprudente y en la exposición de las técnicas de recuperación que permiten subsanar las consecuencias de tal imprudencia y precaverse contra la indefensión que afecta a los ancianos en estado de dependencia económica. Las comparaciones mitológicas y legendarias aducidas no tienden a demostrar un supuesto origen indio o iraní del cuento medieval, sino tan sólo a subrayar la coherencia y la continuidad, dentro de un conjunto de culturas tributarias de una herencia prehistórica común, de una red compleja de representaciones, esquemas narrativos y estructuras mentales. La definición de esta red permite apreciar el alcance de los trasiegos, soluciones de continuidad y reinterpretaciones, y entrever el proceso de transformación y adaptación que agencia el paso del mito al folklore. Esta metamorfosis alquímica se produce exclusivamente al nivel de la tradición oral: exige un sinfín de mudanzas infinitesimales y una flexibilidad formal suficiente para que, insensiblemente los trasvases, asociaciones, dislocaciones y reinversiones tanto al nivel imaginario como ideológico, puedan dar lugar a la constitución global de un tipo narrativo nuevo.

En el caso del cuento que nos ocupa, a las analogías estructurales con el ciclo arcaico se añaden obvias continuidades y transferencias tradicionales: el empalme con la leyenda del rey Lear ha sido subrayado por varios folkloristas ${ }^{42}$, y es particularmente manifiesto en la serie de versiones (que constituye en realidad como un subtipo) en que el anciano sólo tiene hijas y no se despoja de la totalidad de sus bienes por una donación prematura sino por querer dotarlas cuando se casan.

Este caso se presenta en particular en una versión francesa que se encuentra en una traducción versificada de la Disciplina Clericalis ${ }^{43}$. También hemos visto que en el Libro de los Exemplos, Johan Ganança sólo tiene hijas y utanto amava a los yernos que poco a poco les dio todo el oro e la plata e los otros bienes» ${ }^{44}$; este desplazamiento narrativo

42 Cf. F. C. TUbach, op. cit., n." 3006, p. 236 («Lear and daughters») y el tipo Aa-Th. 923 («Love like salt»), motivo M 21 («King Lear judgment»). La relación entre la leyenda de Lear y el cuento Aa-Th. 982 es subrayada por W. Perretr, op. cit., pp. 21-24, H. Schwarzbaum, Studies..., p. 236, id. en Sefarad, 22, 1962, pp. 342-344, y F. H. Von Der Hagen, op. cit., pp. LVIII y ss.

43 Le chastoiement d'un père à son fils (Paris, éd. Soc. des Bibl. fr.: 1824), n." 27, pp. 180-191 («D'un Prodom qui dona tot son avoir à ses deus Filles»). Es cuento adicional que no figura en el texto original de la Disciplina Clericalis.

44 Lo mismo pasa en una de las versiones portuguesas aducidas por T. BraGa lop. cit.. pp. 135 y ss.) y en varias versiones latinas medievales (cf. T. WRIGHT, op. cit., pp. 28-29, donde sólo se menciona una hija). La historia del «testamento de Juan Conaxa», que se lo dio todo a sus dos hijas y a sus maridos, parece haber sido difundida en 
de las hijas hacia los yernos por medio de la dote constituye una transición entre el tipo más corriente, en el que el padre tiene que habérselas con hijos ingratos, y el tema del rey Lear, en que el desgraciado anciano les da a cada una de sus hijas mayores una mitad del reino al casarlas con dos duques y se ve luego desposeído de su regia potestas como consecuencia de la rebelión de éstos.

Otro tipo de transición se encuentra en unos relatos en que el motivo de la invitación al suicidio mediante el regalo de un instrumento apto para ello (elemento característico del cuento del fingido tesoro, coronado por el motivo de la maza en el arca) se combina con el de la hija menor exenta de la ingratitud manifestada por sus hermanas (elemento básico de la leyenda de Lear) ${ }^{45}$ : resulta además sumamente significativo el que el refrán admonitorio (que les aconseja irónicamente a los padres imprudentes y demasiado generosos que se acogoten a sí mismos) sea recordado por el mismo desesperanzado rey Lear en una de las versiones medievales de su leyenda ${ }^{46}$.

Bien se sabe que la historia del rey Lear tuvo amplia difusión en las tradiciones orales, que su tema principal se articuló con ciclos folklóricos tan propalados como el de Cenicienta y de Piel de Asno ${ }^{47}$, y

varios idiomas, como lo atestigua la onomástica de algunas versiones (cf. supra n. 7): en Francia la popularizó su inclusión en las Pia Hilaria de A. Gazet (1619) y en su traducción en lengua vulgar.

45 Ver W. Perret, op. cit., pp. 22-23. Se trata de la versión eslava recogida por Wenzig citada supra n. 38, y de un cuento del Praeceptorium divinum de Gottschalcus Holle, Colonia, 1484, en el que las dos hijas mayores le regalan al anciano una cuerda y un cuchillo para facilitar su suicidio, mientra que la menor le ofrece a su propio hijo para salvarlo (tema que se encuentra en los equivalentes célticos de la leyenda de Yayãti auxiliado por su hija y sus nietos: ver G. DumÉzIL, Mythe et épopée, 2, pp. 345-353): en este texto medieval el padre, que sólo ha simulado la pobreza para poner a prueba la devoción de sus hijas, devuelve los regalos ofensivos a las ingratas, aconsejándoles que ios usen en sus propias personas, y promete a su nieto la totalidad de sus bienes después de su muerte. La inserción del motivo del instrumento letal como regalo, aunque empleado de un modo diverso, revela claramente el estrecho parentesco de estos relatos con el tipo 982. Perrett apunta que la versión de la leyenda de Lear referida en el Livere des Reis de Brittanie parece haber sido afectada por una contaminación con cuentos de esta clase (op. cit.. pp. 23 y $47-48$ ).

46 «Hellas! que joy mal entendu le proverbe qui dist en ceste maniere: De ce bastun ou dun plus gran Soit il feru au front devant, Qui donne tout a son enffant, Que puis lui en va demandant» (Jean de WAVRIN, Recueil des croniques et anchiennes istories de la Grant Bretaigne, I, 2, 31: ver PERRETT, op. cit., p. 22, n. y pp. 72-74). También se asocia a la historia de Lear el mentado refrán en uno de los sermones de Valerius Herberger (PERRETT, p. 124).

47 Ver W/. PerReTt, passim y supra n. 42. Consultar también E. S. Hartland, 
que el esquema narrativo en el que estriba se encuentra en muchos textos: éstos generalmente tienen relación, directa o indirecta, con la leyenda referida por Geoffrey de Monmouth pero originaron a su vez tradiciones orales independientes, pasando a constituir poco a poco una red en la que las referencias literarias o eruditas iban desempeñando papeles cada vez más ínfimos ${ }^{48}$. Por lo tanto, no es necesario suponer una influencia de la literatura escrita en la constitución del cuento del fingido tesoro: es probable que cuando apareció por primera vez en forma literaria ya estuviera difundido un conjunto de tradiciones orales afines (folklóricas y/o folklorizadas) a través de las cuales circulaban y se intercambiaban motivos, secuencias, temas y elementos formulísticos.

5) El cuento del fingido tesoro se entronca con el ciclo indo-europeo del Primer Rey por otro de los temas que comparten, tema distinto del de la donación imprudente aunque estrechamente relacionado con él: el de la oposición conflictual entre viejos y jóvenes.

G. Dumézil y J. Grisward han puesto de manifiesto la importancia de esta tradición en el ciclo relativo a las vicisitudes sufridas por el Soberano de los Primeros Tiempos ${ }^{49}$.

Ya hemos notado que la senectud es motivo esencial, aunque diversamente modulado, en los relatos míticos más característicos del ciclo, siendo el envejecimiento del protagonista sanción de un pecado anterior (Yayāti), u ocasión que da paso a las consecuencias fatales del error inicial (Lear), cuando dicho pecado o error no consiste precisamente (como ocurre en el caso de Aymeri) en negarse a aceptar la vejez ${ }^{50}$.

La recurrencia de este tema y la diversidad de sus empleos manifiestan su antigüedad y su probable carácter fundamental en la prehistoria del ciclo: al parecer el tipo del Primer Rey indo-europeo se relaciona con la idea de un tiempo originario, en que reinaban la inmortalidad y una juventud perpetua, garantizadas y encarnadas por el mismo Soberano,

"The outcast child», The folklore journal, 4 (1886), pp. 308-320 (tipos «King Lear» y "Value of Salt»), y M R. Cox, Cinderella (Londres, 1893), pp. 80-86 y 469-471. Las versiones orientales son examinadas por $\mathrm{T}$. ZACHARIAE, «Indische Parallelen zu König Lears Fragen an seine Töchter», Zeitschrift für Volkskunde, 3 (1931), pp. 141-147: el estudio de la tradición oriental bien muestra que no se puede considerar a Geoffrey de Monmouth como el origen único y absoluto del conjunto del ciclo.

48 Cf. la historia atribuida al emperador Teodosio en algunas versiones de los Gesta Romanorum (C. S. HaRTLAND, op. cit., pp. 312 y ss., W. PerReTt, op. cit., pp. 64-70, y E. FARAL, op. cit., p. 111).

49 Ver J. H. Grisward, Archéologie... pp. 111 y ss. y 124 y ss.; y G. Dumézil, Mythe et Epopée. 2, p. 298.

50 Cf. supra, n. 32. 
que es, ante todo, como maestro del Tiempo, un manipulador de las edades. Surge la crisis cuando el Reino (la Tierra) ya no proporciona el espacio y abastecimiento suficientes para las sucesivas generaciones que se van apiñando en el mismo sitio, y se produce un conflicto entre viejos y jóvenes. La solución obligatoria es un reparto del espacio disponible, el cual implica en muchos casos la expulsión o migración forzosa de los jóvenes, dándose en varias ocasiones la circunstancia de que los ancianos se alían a los más jóvenes contra los hermanos mayores de éstos (o a sus nietos contra sus hijos) ${ }^{51}$ : hemos visto cómo esta dispersión de los hijos, o sea de las fuerzas vivas del reino, puede entrañar un debilitamiento general que repercute especialmente en la persona del Soberano. La buena gestión de esta delicada operación de repartición -que puede acabar en catástrofe individual y socio-cósmica o desembocar en una armoniosa distribución del espacio, asociada a una eficaz complementariedad entre los grupos de edad- es la piedra de toque de la acción del Soberano Primordial, que puede salir enaltecido o disminuido, cuando no anulado, a raíz de las consecuencias de su propia elección y ponderación. Una de estas consecuencias puede ser un total trastocamiento del inicial equilibrio de los poderes: el monarca omnipotente puede verse destituido o privado de lo esencial de su autoridad; al alejar a la juventud o no saber conferirle el debido empleo, la conveniente atribución y retribución, al colocar mal sus inversiones, puede dar pie a la propia senescencia, o pérdida de substancia. Corre peligro, a su vez, de ser rechazado y expulsado por los que ha premiado o castigado con criterio inadecuado. Al mismo tiempo se invierte la relación de las fuerzas en el conflicto entre grupos de edad y la expulsión de los jóvenes se transforma en marginación o eliminación de los ancianos 52 .

6) Esta derivación temática explica los numerosos puntos de contacto que existen entre nuestro cuento del fingido tesoro y el importante ciclo folklórico (cuentos, leyendas, refranes, cantigas, creencias, etc...) relativo al «abandono por senectud» y a la «eutanasia familiar», del que estudié en otro trabajo las raíces antiguas, las versiones medievales y algunas formas orales modernas ${ }^{53}$.

51 Sobre este ciclo de leyendas y representaciones ver G. DumÉzIL, Mythes et dieux des Germains (Paris, 1939), pp. 65-78; y J. GRISwARD, op. cit., pp. 111-114.

52 Sobre las relaciones entre estas dos formas de mutilación social en leyendas y mitos germánicos, ver G. DuMÉzıl, Mythes et dieux..., loc. cit. (generalmente la migración de los jóvenes es presentada como una alternativa inteligente a la exterminación de los ancianos en los casos de competencia alimentaria).

53 Ver F. DELPECH, «L'élimination des vieillards: recherches sur quelques versions 
Se sabe que en este conjunto de narraciones y representaciones, que tuvo especial desarrollo en las partes septentrionales y occidentales de la península ibérica ${ }^{54}$, así como en Europa central y en extremo Oriente, se destacan algunos cuentos-tipos - representados tanto por versiones literarias (exempla, novelas cortas, fabliaux) como folklóricas, orales y tradicionales - en los que se evocan diversos grados de eliminación (o marginación) del anciano inepto para el trabajo y dependiente de la benevolencia de los hijos.

6.1. Se describe por ejemplo el estado de humillación y relegación familiar que se le impone al anciano en su casa cuando ya no se le permite comer en la mesa con los demás y se le obliga a quedarse sentado cerca del hogar y a comer en una escudilla de madera ${ }^{55}$ : una observación acaso no premeditada de su nieto, que pretende fabricar otra escudilla igual para dársela a sus propios padres cuando hayan alcanzado la misma edad del abuelo los hace reflexionar y los mueve a reintegrar al anciano en la comensalidad familiar ${ }^{56}$.

El mismo tipo de relegación y denegación de la dignidad doméstica, del que sabemos que corresponde a prácticas sociales efectivas en ciertas regiones ${ }^{57}$, se retrata muy precisamente en algunas versiones de nuestro cuento del fingido tesoro, que mencionan el característico motivo de la escudilla ${ }^{58}$.

ibériques d'un cycle folklorique traditionnel» (de próxima publicación en las Actas del coloquio Littérature orale, Paris, Fundación Gulbenkian, 1986). Remito a este artículo donde se citan las principales fuentes, primarias y secundarias.

5.4 lbid. passim. y F. BOUZA BREY, «El tema del abandono por senectud en el folklore gallego-portugués», RDTP. I (1944), pp. 496-513.

55 Tipo Aa-Th. 980 B («Wooden drinking cup for old man»). Hay versión española antigua en Timonf:DA, El Buen Aviso, 2, n." 74, p. 243 de la ed. cit., y versiones folklóricas modernas en Galicia (F. BOUZA BREY, op. cit., p. 499; y Contos populares da prozincia de Lugo, Vigo, 1979, p. 64, n. 64).

56 Notar el tema de la complicidad, consciente o involuntaria, entre el nieto y el abuelo, que ya hemos apuntado en varias versiones del ciclo del Primer Rey.

57 En particular Galicia, Bretaña y Languedoc: ver C. Lisón Tolosana, Antropología cultural de Galicia (Madrid, '1979), p. 228 («no comen en la mesa con los demás sino en un rincón»).

58 Cf. la versión latina reproducida por T. WRIGHT: "Hic primo anno senem in mensa secum collocavit, de unaque scutella comedebant, et de eodem eum vestitit». En varias versiones de $\mathrm{Aa}-\mathrm{Th}$. $980 \mathrm{~B}$, se especifica que el recurrir a la escudilla es medio para subalimentar al anciano y ahorrar gastos: del mismo modo mencionan algunas versiones de Aa-Th. 982, que el protagonista pasa hambre después de la imprudente donación (en la traducción francesa de las Pia Hilaria. A. Gazet indica que a Jean Conaxa «à 
6.2. En otro cuento-tipo de este ciclo, cuya versión más conocida es el fabliau medieval de la "Housse Partie», se refiere el caso de un padre que le da toda su hacienda a su hijo, para que pueda casarse con una joven de noble estirpe, y que comparte con el matrimonio su propia casa. Poco a poco la nuera empieza a sufrir con creciente impaciencia la cohabitación con el anciano, al que desprecia, e instiga a su esposo a que lo vaya confinando en partes más y más apartadas e incómodas de la casa. Al final consigue que el hijo decida expulsar al padre y le mande a mendigar por las calles. Es otra vez el nieto el que induce a su padre a revisar su decisión, a cambiar su conducta, al cortar la manta que tiene que entregar al abuelo en el momento de la expulsión y declarar que se queda con la mitad para dársela a su padre cuando le toque el turno ${ }^{59}$.

En este cuento, del que existen varias versiones ibéricas, antiguas y modernas (folklóricas) ${ }^{60}$, se articulan el tema de la ingratitud, propio de la tradición de los exempla, y la advertencia, de trasfondo ideológico tradicional y burgués, contra los casamientos desiguales y el peligro de las donaciones: la situación inicial es, por lo tanto, idéntica a la del cuento del fingido tesoro, en particular en las versiones de éste donde el padre tiene sólo un hijo (hemos visto que es el caso en el cuentecillo de Timoneda) ${ }^{61}$ y es más víctima de las artimañas de su nuera y de la debilidad del mozo, demasiado sometido al matriarcado doméstico impuesto por su esposa, que de su ingratitud ${ }^{62}$.

peine lui restait-il une rave cuite et de l'eau pour son breuvagen, y que cuando sus hijos lo ven llegar, ocultan los platos buenos preparados para la cena laqui hay reminiscencia evidente de Aa-Th. $980 \mathrm{D}$ - -Meat springs as a toad on the face of an ungrateful son»-- que, marginalmente, forma parte del mismo ciclo folklórico).

59) Tipo Aa-Th. $980 \mathrm{~A}$ («The half carpet»). El tipo global 980 («Ungrateful son reproved by naive actions of own son: preparing for old age») es estudiado por J. Bolte y G. Polf́vkA, Anmerkungen zu den Kinder und Hausmarchen der Bruder Grimm (Leipzig, 1913-1931), t. 2, pp. 135-140.

60 Libro de los Exemplos (ed. cit) n. 337, El espéculo de los legos (ed. Mohedano Hernández) n." 439, у J. de MAL LARA Filosofía vulgar (ed. A. Vilanova) t. 3, pp. 33 34, F. Bouza Brey, op. cit., p. 496 y ss., etc. Ver F. DelPeCH, op. cit.

61 Lo mismo pasa en la versión catalana recogida por Amades y en la versión italiana antigua publicada por P. Rajna. En la mayoría de las versiones del tipo 982 se mencionan varias hijas (como en el tipo «Lear») o varios hijos, a veces sólo una hija (T. Braga, T. Wright). Me parece evidente que las versiones en que no hay más que un hijo proceden de una contaminación con el tipo $980 \mathrm{~A}$, o por lo menos reflejan una influencia ejercida por este tipo.

62 El tema de la nuera hostil y de la perversa influencia matriarcal en el funcionamiento del linaje agnático es la constante de muchas versiones del tipo 980 A y de 
Se nota especialmente el parentesco entre ambos cuentos en las versiones respectivas donde se describe el gradual proceso de marginación del anciano, al que primero se le excluye de la cabecera de la mesa, y a continuación de la misma mesa y de las habitaciones principales de la casa, hasta que se le confina en un tugurio informe cuando no en un cuchitril situado debajo de la escalera, cerca del establo o junto a la calle ${ }^{63}$.

6.3. El simbolismo espacial que permite una visualización gráfica del proceso de decadencia y exclusión se explota de modo más sistemático en un tipo narrativo afín, en el que se cuenta la expulsión efectiva del anciano fuera de su casa, a veces fuera de la misma comunidad social: en algunas versiones se le quiere abandonar en la montaña con una manta y una borona. Generalmente se interrumpe al fin la operación y se reintegra al anciano a raíz de una observación formulada por éste (que alude a la suerte parecida sufrida por su propio padre, y le deja prever a su hijo que le pasará lo mismo cuando llegue a viejo); en este caso, como en los precedentes, un suceso inesperado le hace tomar conciencia al hijo de la necesidad de detener el proceso, ya que éste amenaza con tansformarse en un mecanismo a cuyo funcionamiento teme verse sometido a su vez cuando llegue a viejo ${ }^{64}$.

tipos afines. En la versión mejicana del tipo 982 (H. T. WHEELER, op. cit.) la conclusión es modificada por una extensión de dicho tema: los tres garrotes dejados por el anciano en el cajón no sirven para escarmentar a los padres imprudentes, sino para que los hijos les den una sonada paliza a sus esposas por haberlos aconsejado mal.

63 Recuérdese que en la versión de Timoneda se menciona indirectamente la primera etapa de la exclusión al precisar que «en sentir que el viejo tenía dineros [...] le servían y honraban, poniéndole a cabecera de mesa». El mismo detalle figura en la versión de Amades ( $« . .$. el va treure de cap de taula per posar-s'hi ell»...). La versión latina reproducida por $\mathrm{T}$. Wright evoca la totalidad del proceso: «Hic primo anno... (cf. supra $\mathrm{n}$. 58). Secundo vero anno posuit eum in fine mensae et cibavit et vestivit de pejori. Tertio anno, positus fuit cum pueris super terram proximus pessimis, et $[\ldots]$ eum de camera ejecit, et in tugurio juxta portam eum habitare coegit». El mismo tipo de exclusión progresiva está compendiado en la versión de Aa-Th. $980 \mathrm{~A}$, que se puede leer en el Espéculo de los Legos: «E el fijo asentava al comienço al padre a la cabecera de la mesa, e dende a tienpo ponialo en medio e despues ponialo a cabo de la mesa, e dende a mas tienpo ponialo entre siervos, e despues pusole una camilla tras la puerta de la casa.".

64 Tipo Aa-Th. $980 \mathrm{C}$ («Dragging old man only to thershold»). Hay versiones literarias españolas (J. TimonedA, El Buen Aviso..., 2, n." 4, p. 221; también se encuentra en el Diálogo en laude de las mujeres de Juan de ESPINOSA y en varias versiones folklóricas modernas, tanto en España como en Portugal y América): ver F. DELPECH, op. cit. 
Como el cuento del falso tesoro, este tipo-narrativo sirve frecuentemente de ilustración para un dicho admonitorio («Hijo eres, padre serás; según lo hicieres, así lo verás») y en muchas versiones se explica la hostilidad del hijo, y sobre todo de la nuera, hacia el padre por los problemas que va planteando la convivencia del joven matrimonio y del anciano en la misma casa: en todos los casos resulta patente que esta casa es la patrimonial, pero que su amo y propietario se ha dejado despojar, en la propia vivienda, de sus derechos y privilegios.

Aquí no se suele mencionar una donación: frecuentemente los malos tratamientos y la exclusión se explican por la existencia de una supuesta tradición o costumbre repetitiva, de carácter regional y arcaico, según la cual se confina o expulsa a los ancianos cuando ya no sirven para el trabajo.

El contexto social en el que se sitúa el relato es en general de tipo rural y estriba en una economía de subsistencia en que las reciprocidades son limitadas por un estado continuo de carencia alimentaria: por lo tanto, la decisión del hijo, cuando renuncia a expulsar a su padre, cobra la dimensión de un acto heroico y civilizador, que instaura un nuevo tipo de sociabilidad, y el cuento se presenta como un mito de fundación, una afirmación de la solidaridad de linaje (patrilineal) y de la necesaria convivencia de las generaciones en un espacio común y simbólicamente jerarquizado.

Así que este cuento parece constituir uno de los eslabones entre las mitologías indo-europeas relativas a los tiempos primordiales que mencionamos más arriba y tipos narrativos parecidos al que moviliza el tema del tesoro ficticio: como aquéllas se refiere - aunque en grado menor, restringido al nivel del linaje - al problema de la sobrepoblación, de la competencia alimentaria y de la oposición conflictual entre grupos de edad (y por lo tanto a la eventualidad de una expulsión de parte del cuerpo social); como éstos plantea este problema en términos de cohabitación doméstica y de convivencia intergeneracional.

En una sociedad cristiana, mercantil y urbana, en la que las reciprocidades se proyectan en relaciones monetarias y morales a la vez, los temas de la ingratitud y de la herencia pasan al primer plano: las mediaciones jurídicas, los artificios del ingenio y de la ficción testamentaria toman el relevo de la elemental astucia por la cual el anciano expulsado conseguía hacerle comprender a su hijo que, al fin y al cabo, tenía interés en no cometer un acto o promover una costumbre que fatalmente se volverían en su contra algún día ${ }^{65}$.

65 En el tipo $980 \mathrm{C}$ y en todos los tipos afines, el anciano consigue salir de apuro 
6.4. Ahora bien, en la tradición oral gallego-portuguesa estos cuentos relativos a la marginación o exclusión de los ancianos se han combinado con un tema legendario arcaico característico de varias sociedades indoeuropeas de la Antigüedad y todavía vigente en los folklores de algunas regiones donde se han mantenido rasgos culturales «primitivos»: este tema, que se puede rastrear desde el Japón hasta el mundo céltico, y que tuvo especial desarrollo en las culturas escíticas (que, al parecer, lo han propalado tanto hacia el oriente como hacia el occidente), es el de la occisión obligatoria de los ancianos a partir de una edad determinada ${ }^{66}$.

Hemos visto que en varias versiones de los cuentos que acabamos de resumir se alude a una costumbre tradicional de abandono por senectud y que el hijo ingrato no se contenta con expulsar al anciano fuera de la casa solariega, sino que lo conduce a una montaña salvaje y lo abandona allí con unas pocas provisiones. En Galicia y en Portugal este tema se relaciona con leyendas topográficas que precisan que, en tiempos antiguos, tal o cual lugar (peña, montaña, escollo en el mar) servía tradicionalmente para dicho abandono. Al parecer, esta tradición - desarrollada en cuentos, leyendas, creencias, etc.- se entronca con prácticas sacrificiales efectivas que tuvieron vigencia en los sectores más «primitivos» de las sociedades guerreras y migratorias de la Antigüedad y de la Edad Media (alanos, tribus germánicas y escandinavas, grupos ét-

(con 0 sin intervención, ingenua o intencionada, del nieto) al hacer que se produzca una revolución en la mente de su hijo: iluminación moral y sobre todo atinada aprehensión de su propio interés. En el tipo 982 el mismo resultado se logra mediante una superchería y la excitación de la codicia de los herederos: este cuento resulta mucho más pesimista y desengañado, al parecer, por situarse en el contexto de una sociedad individualista y mercantil en que se han alterado los valores tradicionales y donde triunfa el egoísmo en su forma más cínica. Ya parece traslucirse el universo de Volpone. A la demostración de la complementariedad entre el interés individual y las solidaridades horizontales y verticales (como armoniosa mecánica de encadenamientos y reciprocidades) se ha. sustıtuido la complacida desarticulación de los artificios que uno pone en obra para hacerse con los bienes ajenos o, en el mejor de los casos, defender su propia hacienda. Se pasa de una reciprocidad regulada por la tradición y el equilibrio normal de los intereses respectivos, a una reciprocidad obtenida a la fuerza.

(x) Este tema es el elemento básico del tipo Aa-Th. 981 ( «Wisdom of hidden old man saves kingdom»): no se han recogido versiones de este tipo en España, pero su presencia en Méjico (H. T. WHEelER, op. cit. pp. 6-7, n." 3, «El decreto del rey») y la incidencia del tema en las distintas formas ibéricas del tipo general 980 indican que, de una forma u otra, esta tradición narrativa tuvo vigencia en España. La versión que consta en el Libro de los Exemplos (n. 401) es de origen literario y erudito. En muchas versiones orientales y centroeuropeas el tipo 981 se combina con el $980 \mathrm{~A}$, y la manta es sustituida por una cesta, que se utiliza para llevar al anciano a la montaña y, ocasionalmente, para echarlo a un precipicio. Ver bibliografía en F. DELPECH, op. cit. 
nicos del Cáucaso, etc.) ${ }^{67}$, y no pocas veces se indica que los jóvenes no se contentan con abandonar a los ancianos en la sierra sino que los matan, echándoles en algún precipicio o acogotándoles con algún instrumento contundente.

Estas prácticas son extrañas, por supuesto, al mundo urbano y burgués donde se sitúa el cuento del fingido tesoro. Tanto más curioso e interesante resulta el constatar que, en la mayoría de sus versiones, este cuento pone de realce un elemento formulístico que alude precisamente, aunque de un modo indirecto, a dicha práctica e introduce el mismo instrumento con el que se solía poner en obra, acompañado por un mensaje incitativo que no deja dudas en cuanto a la función del objeto.

En efecto, este «mazo» ocultado en el arca, con el que se pretende que los padres demasiado generosos deben darse un golpe en la cabeza, es arma de larga historia y arcaico simbolismo. Es obviamente heredero directo del instrumento ritual al que aluden muchas de las tradiciones que acabamos de mencionar: es el «holy mawle» inglés, el «heilige hammer» germánico, y más destacadamente el famoso "mael beniguet» de los bretones ${ }^{68}$. En este último caso es notable la cristalización legendaria que se realizó alrededor del insólito objeto, que generalmente se presenta como una bola de piedra conservada en alguna que otra iglesia o capilla de Bretaña: se cuenta en ciertas tradiciones locales que antaño los druidas lo usaban para acogotar a los ancianos, y que dicha occisión se verificaba en la cumbre de una montaña determinada ${ }^{69}$. En realidad parece que estos objetos sólo se usaban para aliviar la agonía, por mero contacto

67 Ver F, PAUDLER, «Alten-und Krankentötung als Sitte bei indogermanischen Völkern», Wörter und Sachen, 17 (1936), pp. 1-57; y K. E. MülleR, «Zur Frage des Altentötung im Westeurasiatischen Raum», Paideuma, 14 (1968), pp. 17-44.

68 Sobre el «holy mawle», ver W. J. THOMS, Anecdotes and traditions illustrative of early english history and literature (Londres, 1939), pp. 84 y ss. (Según la leyenda, servía para rematar a los moribundos y estaba colgado detrás de la puerta de la iglesia). Sobre su equivalente germánico: J. GRIMM, «Der heilige Hammer», in M. Haupt (ed.), Zeitschr. f. deut. Altert. (Leipzig, 1845), t. 5, pp. 72-74, K. E. MÚller, op. cit., pp. 19 y ss., 33 y 39, F. Paudler, op. cit., pp. 10, 40; y P. SARTori, "Die Sitte der Altenund Krankentötung», Globus, 67 (1895), pp. 128-130. Puede ser una porra, un martillo o un hacha. Consultar también F. H. Von Der HaGeN, op. cit., pp. LXIV-LXVI.

69 Ver F. LE Roux, «Le Mel Benniget», Ogam, 3 (1951), pp. 164-166; J. GricourT, «Un Mell Benniget gaélique», Ogam, 7 (1955), pp. 155-170; P. LE Roux, «Note étymologique à propos du Mell Benniget», ibid., pp. 171 y ss. Todavía se pueden consultar Aveneau de LA Grancière, La massue sacrée ou Er Maël Beniquet (Saint Brieuc, 1900), y J. Loth, «Le fameux Mell benniget», Annales de Bretagne, 19 (1904), p. 246. En Bretaña la tradición legendaria tiene especial arraigo en la región del Mané Guen (montaña blanca), cerca de Guénin, supuesto lugar tradicional del sacrificio. 
con la cabeza del moribundo, y que tal ceremonia era aplicación del sistema de creencias que le atribuye virtud mágica a ciertas piedras ${ }^{70} \mathrm{e}$ importancia especial a la cabeza como receptáculo de la fuerza vital del individuo ${ }^{71}$.

Al parecer, este conjunto simbólico se remonta hasta las religiones célticas, en las que consta el tipo de un dios armado con un mazo, generalmente llamado Sucellus, entidad mítica ambivalente, ya que se relaciona al mismo tiempo con la muerte y la inmortalidad, con el mundo subterráneo como infierno y como fuente de la fertilidad y de la vida ${ }^{72}$. Cabe preguntarse en qué medida este dios, al que se ha identificado con Dis Pater, el mítico antepasado de la raza gala, puede ser una variante céltica y teológica del tipo del «Primer Rey», en el que no es difícil vislumbrar que es proyección humana de una entidad cosmogónica ${ }^{73}$.

Lo que sí es cierto es que este motivo arcaico del mazo ocultado en el arca se encuentra desde las primeras versiones del cuento, ya que se menciona en casi todas las formas del refrán o dicho admonitorio

70 Cf. P. SEBIllot, Folklore de France (Paris, reed. 1968), t. 4, pp. 75 y ss.; y P. SAINTYves, Corpus du folklore prébistorique en France (Paris, 1934-1936), t. 2, pp. 118, 442.

71 Ver P. LAmBrechts, L'Exaltation de la tête dans la pensée et dans l'art des Celtes (Brujas, 1954), y F. Del.PECH, op. cit., n." 55, 71 y 80. El rito pontifical que consiste en golpear la frente del Papa difunto con un martillo de plata es probablemente superviviencia de una ceremonia análoga y de sus correspondientes y pretéritas creencias.

72 Ver P. LAMBRECHTS, Contribution à l'étude des divinités celtiques (Brujas, 1942), pp. 100-116; M. E. LINCKENHELD, «Sucellus et Nantosvelta», Revue de l'Histoire des Religions, 1929; M. F. Heichelheim, J. E. Housman, «Sucellus and Nantosuelta in Mediaeval celtic mythology», L'Antiquité Classique, 17 (1948); y C. GUYONVARC'H, F. LE Roux, la souveraineté guerrière de l'Irlande (Rennes, 1983), pp. 114-124. La ambivalencia del dios es subrayada por Linckenheld y Lambrechts (dios celeste/dios infernal), por Heichelheim y Housman (quienes insisten en la multiplicidad de las funciones divinas de Sucellus que parece ser proyección de un gran dios «nacional» céltico a la par que «a pre-indogermanic deity of Western Europe who was assimilated to indogermanic celtic beliefs») y por H. HubERT, que subraya la relación del dios con las bebidas de inmortalidad ( Nantosvelta, déesse à la ruche», Mélanges $R$. Cagnat (Paris, 1912), pp. 281296.

Cf. S. BOUCHER, «Sucellus = Dispater ? Remarques sur la typologie et les fonctions du dieu gaulois», Revue Belge de Philologie et d'Histoire, 54 (1976). No se puede descartar la hipótesis de un prototipo indo-europeo del dios del mazo y de su relación primitiva con el ciclo de representaciones relativo a la eliminación de los ancianos. Cf. A. Grenier, «Le dieu au maillet gaulois et Charun», Studi Etruschi, 24 (1955-1956); F. de RUYT, Charun, démon étrusque de la mort (Bruselas, 1934), pp. 141-144, 180-193 y 195-253; y B. LinCOLN, "The Lord of the Dead», History of Religions, 20 (1981), pp.
224-241. 
en que parece fundarse el relato ${ }^{74}$ : es probable que existiera en la memoria colectiva y que su adscripción a unos tipos narrativos y paremiológicos fuera antigua ${ }^{75}$. Siendo dicho motivo elemento fundamental de la narración, ya que en él se invierten todo el humorismo y toda la moraleja que se ventilan en la breve anécdota, es de suponer que, por vías necesariamente orales (no figura el motivo, que yo sepa, en ninguna otra producción literaria), el cuento se enraíza en el conjunto de antiguas tradiciones folklóricas relativas a la eliminación de los ancianos ${ }^{76}$.

74 Es de notar la coincidencia entre las denominaciones bretonas y británicas del fatal instrumento («mael», "mawle») y los términos que se encuentran más corrientemente en los cuentos para designar el objeto dejado en el arca: «mael» (T. WRIGHT, loc. cit.), «mail» (traducción francesa de la Disciplina Clericalis), «malho» (T. BRAGA, loc. cit.), «malleus» (versiones latinas).

75 El motivo del mazo parece ser propio de las versiones occidentales (¿de origen céltico?) del cuento, que tienen más coherencia y regularidad formal que las orientales, donde se notan muchas variaciones en cuanto a los protagonistas y situaciones. Es preciso observar, además, que en algunas versiones (por ejemplo, la de Timoneda) se debilita la eficacia narrativa del tipo al obliterarse el motivo final, o al ser sustituido el mazo por unas piedras o por un montón de arena (¿por influencia del tipo 1617?): esta transformación puede explicarse, sin embargo, por el hecho de que existe cierta ambigüedad en la naturaleza supuesta del «mael», que es martillo o mazo, pero en Bretaña se reduce frecuentemente a una mera bola de piedra, siendo al fin y al cabo la piedra el elemento determinante de la operación por su propia fuerza mágica. Notar que en la versión mejicana, donde aparecen tres "garrotes», éstos van acompañados por tres piedras, ya inútiles, que atestiguan la persistencia de la tradición y del implícito simbolismo que entraña.

76 Además del intercambio de motivos recurrentes (donación, expulsión progresiva, hostilidad de los yernos y nueras, etc.) que se puede observar entre los debatidos tipos, es de notar que tienden a coexistir y a atraerse recíprocamente en una misma área cultural (en Galicia, por ejemplo), reflejándose este tropismo cíclico en colecciones como las de Timoneda, donde se encuentran a la vez versiones de Aa-Th. $980 \mathrm{~B}, 980 \mathrm{C} \mathrm{y}$ 982 (cf. supra n. 1, 55 y 64). Además, en determinados casos, se funden en un mismo relato encadenado los distintos tipos del ciclo, como ocurre en un largo cuento griego en el que se empieza con la historia de la media manta y se prosigue, después de la expulsión del protagonista, que en este cuento viene a ser efectiva, con la anécdota del fingido tesoro, para acabar con una reunión de ancianos que comparten la misma experiencia de la ingratitud filial (uno de ellos incluso escapó a una tentativa de asesinato) y concuerdan en admitir que los ancianos deben conservar el control de su hacienda hasta su muerte. Se nota la influencia eclesiástica en el final del cuento, donde se propone una variante del tema central de Aa-Th. 982, al referirse la historia de un anciano que consigue que cambien de comportamiento sus herederos cuando, con la complicidad de un sacerdote, les hace creer que va a dejar todos sus bienes a la Iglesia: J. Zarraftis, Forty-five stories from the Dodekanese (ed. R. M. DAwKINS) (Cambridge, 1950), n." 18, pp. 225-236 ( «The parents»). 
7) He tratado de demostrar, en otro ensayo, que la pervivencia privilegiada del ciclo relativo a la eliminación de los ancianos en las tradiciones orales de algunos sectores de la península ibérica (Portugal, Galicia) se explica por ciertas peculiaridades antropológicas y sociales de los grupos étnicos que poblaron estas regiones.

Descartando el problema de las probables influencias de elementos culturales migratorios neo-escíticos, germánicos y célticos que se ejercieron a lo largo de los siglos en estas sociedades (y que explican que el mentado ciclo de tradiciones orales que se ha desarrollado en ellas tenga más analogías con los folklores de otras culturas que con la tradición literaria vernacular), fijémonos en los datos que pueden justificar el relieve que cobra en dichas culturas el problema de la transmisión de los bienes por dote, donación o herencia y la consiguiente problemática de los conflictos entre grupos de edad.

7.1. Ya se sabe que en la península ibérica en general a lo largo de su historia ${ }^{77}$, y en ciertas regiones del Noroeste en particular hasta épocas muy recientes ${ }^{78}$, ha reinado un sistema sucesorio especial que desempeñó un papel esencial en la estructuración familiar y mental del grupo: la institución de la «mejora» (o ventaja legitimaria). Según este sistema de origen visigótico, que se opone al Derecho Romano por sustituir la sucesión obligatoria a la libertad testamentaria, se da al testador la posibilidad de «mejorar» en una proporción determinada la parte de la herencia atribuida a uno (o más) de sus hijos a costa de los demás.

En el norte de España esta institución se asoció a prácticas locales, especialmente difundidas en ciertos aspectos del derecho consuetudinario vasco, que tendían a desposeer al padre de sus bienes y derechos en provecho del heredero directo, pasando éste a sustituir al anciano como señor de la casa: sigue la convivencia doméstica en la casa patrimonial pero se produce una inversión en la relación de poderes y el anciano se transforma en una especie de pensionista en su propio solar ${ }^{79}$. Se pasa así insensiblemente de la «co-señoría» a un sistema de dependencia.

El régimen de la mejora tiende a identificarse con este sistema cuando dicho mejoramiento se hace antes de morir el testador y se asemeja a una donación o herencia anticipada, especificándose que el heredero

\footnotetext{
77 Ver G. de LACOSTE, Essai sur les «Mejoras» ou Avantages Légitimaires dans le Droit espagnol ancien et moderne (Paris, 1910).

78 Cf. C. Lisón Tolosana, op. cit., cap. 5-8.

79 Ver bibliografía en F. DeLPECH, op. cit., n. 92. Esta práctica tenía como objeto la buena conservación del patrimonio y la preservación de la herencia.
} 
mejorado tiene que «casarse en casa», o sea convivir, a la par que su mujer y sus hijos, con sus padres en la casa patrimonial.

El resultado de este proceso es antagonizador: el hijo mejorado tiene que trabajar para explotar sólo un patrimonio del que es responsable pero que todavía no le pertenece realmente, ya que el padre conserva su autoridad y su control, y debe mantener al anciano, renunciar a tener su propia casa y dejar que su esposa haga de sirvienta en una familia que la considera como una extraña. Esta situación infantilizadora se invierte cuando el anciano ya no tiene posibilidad de imponer su autoridad y deja a la fuerza que su hijo se apodere del mando doméstico y a veces cese de acallar su más o menos latente agresividad. Esta estructura familiar condiciona los sentimientos individuales y, como mostró muy bien C. Lisón Tolosana, genera situaciones conflictivas y relaciones de fuerzas en las que al más débil no le queda más que el fingimiento, el secreto y el engaño ${ }^{80}$.

Una variante del mismo sistema, aunque sin mejoramiento individual ni convivencia doméstica, es la llamada «congra» que implica donación total de los bienes a todos los hijos por partes iguales a cambio de una obligación colectiva de corresponder con una renta vitalicia o con prestaciones alimentarias y médicas ${ }^{81}$. Resulta frecuentemente, en este caso, que cuando los padres tardan en morir, los herederos se cansen y traten de endosarse mutuamente la responsabilidad del hospedaje y del mantenimiento de los viejos, tanto más desprovistos de recursos cuanto menos capaces de ofrecer algo más a cambio de los servicios que esperan.

7.2. Los cuentos relativos al peligro entrañado por las donaciones prematuras aluden claramente a situaciones de este tipo $y$, a través del prisma de su tradición mitológica y folklórica propia, reflejan los conflictos generados por ciertos desajustes en el sistema sucesorio ${ }^{82}$.

80 C. Lisón Tolosana insiste en la estrategia del secreto que manejan los ancianos para lograr el trato esperado: «A mayor secreto, más extensa expectativa, y a mayor expectativa mejor comportamiento esperan los padres de los hijos» (op. cit., p. 229). Es la lógica misma del cuento Aa-Th. 982.

81 Ver C. Lisón Tolosana, op. cit., p. 182; y V. Risco, «Etnografía: cultura espiritual», en R. Otero Pedrayo (ed.), op. cit., t. 1, pp. $577-578$ (donde se cita la interesante versión gallega de Aa-Th. 982 que mencionamos arriba como ejemplo de los cuentos satíricos alusivos a los inconvenientes y peligros de este tipo de donación).

82 Notar que en el Buen Aviso I (n." 45) de Timoneda se encuentra otro cuento análogo, en el que se trata de «cierto mercader» que, "porque casase honradamente un hijo que tenía, hízole donación de todos sus bienes con albarán de su mano, y por semejante necedad el hijo y nuera le trataban mal». Consigue hacerse restituir la donación 
Hay que notar, en efecto, que, en muchas versiones del cuento del fingido tesoro, la donación implica un contrato más o menos tácito y se considera como compensada por un compromiso de parte de los beneficiarios ${ }^{83}$.

La donación es, en general, indiscriminada y no implica «mejora», excepto en los casos más o menos derivados de la leyenda de Lear, en los que se deshereda, total o parcialmente, a la hija que se resistió a la adulación. Pero cabe observar que, en las versiones caracterizadas por la multiplicidad de los herederos, la astucia que se pone en obra a menudo sirve para suscitar una competencia entre ellos. Esta rivalidad sólo se explica si se supone que el anciano tiene la posibilidad de «mejorar» a alguno de ellos en el momento del reparto definitivo, añadiendo un testamento final individualizado a la donación global indiscriminada ${ }^{84}$.

Hemos constatado además que la ingratitud de los hijos se manifiesta a menudo a través de los problemas de convivencia doméstica: como en el sistema del "casamiento en casa" los hijos e hijas viven con sus cónyuges en la casa del padre, o mejor dicho en la casa patrimonial, ya que, en la mayoría de las versiones, por haber hecho donación de sus bienes, resulta ser el padre el que vive en casa de sus hijos, una casa que antes fue suya pero ya no lo es, o por lo menos una casa en la que ha perdido la autoridad señorial ${ }^{85}$. En estos casos el problema

mediante una astucia algo rebuscada (que implica un supuesto bofetón y un escándalo público: «... por jamás quiso decir quién le había dado, hasta en tanto que el hijo le restituyó la donación, y la rompió, diciendo que lo hacía por restaurar los bienes, por si mataba a quien le había hecho tal afrenta»). Al final declara: "Tú, hijo, eres el que me diste el bofetón, pues teniendo convidados, en lugar de ponerme a la cabecera de mesa, me pusiste de guardaplata, ahora harás lo que yo quiero, y no yo lo que tú quieres...». Observar la condición mercantil del protagonista, el aparato jurídico movilizado y, otra vez, el simbolismo de la «cabecera de mesa». Aquí también se menciona que la donación se hace para lograr un casamiento honroso.

83 En la versión mejicana, el padre justifica así el reparto de su hacienda: «... le voy a dar lo que le corresponde a cada quien y después me darán lo que vaya necesitando» (H. T. WHEELER, op. cit.). Esta perspectiva corresponde aproximadamente al sistema de la «congra».

84 Cf. supra n. 35. Si no se postula un sistema más o menos análogo al de la «mejora» no se entiende por qué el hijo -o los hijos- van a cambiar de conducta ya que, de todas formas, heredarán después de la muerte de su padre lo que a éste le haya quedado después de la donación. A no ser que se suponga que temen verse despojados de esta herencia al hacer el padre un testamento o una donación del dinero suplementario a la Iglesia por ejemplo (algunas versiones sugieren esta posibilidad).

85 En muchas versiones se presenta esta situación de convivencia doméstica (Wright, Timoneda, Rajna, Risco, Amades, Braga): el esquema patri-local es idéntico en la mayoría 
del protagonista es ante todo recuperar esta autoridad, reconquistar el puesto perdido, reflejándose en su contienda el proceso agonístico que opone el padre al hijo mejorado y casado en casa cuando la senectud del primero le hace perder progresivamente el mando de los asuntos domésticos ${ }^{86}$.

Esta situación no se encuentra, sin embargo, en todas las versiones: no es imposible que resulte de una elaboración secundaria y que el tipo primitivo fuera reconstruido con motivo de la influencia ejercida en él por tipos afines (como el de la «Housse partie») y de la intervención del motivo de las dotes excesivas, que procedería de preocupaciones propias de las sociedades medievales y posmedievales. En efecto, en muchas versiones el esquema inicial es distinto: el padre no convive con su(s) hijo(s), ya que sigue teniendo su casa propia ${ }^{87}$, o se instaura un sistema de rotación alternativa según el cual el anciano, que ya no posee ninguna morada fija, va a vivir sucesivamente en las casas respectivas de sus hijos o yernos ${ }^{88}$. En ambos casos el protagonista tiene ocasión de com-

de los cuentos del ciclo relativo a la expulsión de los ancianos. El parentesco con el tipo Aa-Th. $980 \mathrm{~A}$ ( «Half carpet») es aquí particularmente notorio.

86 Notar que en estas versiones se encuentra más frecuentemente el caso del padre con hijo(a) único(a) (Timoneda, Amades, Rajna, Wright), pero, como lo apuntaba $P$. Rajna, es probable que este esquema no sea primitivo y proceda de una simplificación, debida acaso, a una contaminación con Aa Th. 980 A.

87 En la versión mejicana se especifica que «antes de heredarlos él hizo una casita pa irse a vivir él solo». Rajna observaba que el detalle de la casa propia del padre debió desaparecer cuando se impuso el tipo del padre con hijo(a) único(a), ya que sólo se justificaba cuando se trataba de reunir a varios hijos en un mismo sitio para hacerlos testigos de la comedia del fingido tesoro. Por otra parte, resultaba incongruente con el postulado de una donación total. En todas las versiones en que el padre tiene residencia propia y separada se nota en efecto que hay varios(as) hijos(as): traducción francesa de Disciplina Clericalis, Libro de los Exemplos, A. Gazet, G. Dumézil, J. Zarraftis, etc. La extensión y antigüedad de este subtipo permite suponer que corresponde a la forma primitiva del cuento (?).

88 En la versión griega recogida por Zarraftis el protagonista describe así el contrato: «I have four sons, all married, and my household goods I have divided among them all, and I have set nothing aside for myself, and they promised to entertain me, one for a week in his guest room, and the next one for a week and the third the same and the fourth" (trad. Dawkins, p. 228. Otro de los ancianos que aparecen en esta versión señala que en la casa de su nuera, «they have a separate little house for me with my bed in it», p. 230). En la versión turca recogida por Dumézil, el viejo les construye una casa a cada uno de sus tres hijos ( J'ai trois fils, jhabiterai tantôt là, tantôt là») y no tarda en darse cuenta de que cada uno trata de eludir el compromiso («Quand il allait chez un de ses fils, la femme de celui là: "N'as tu pas d'autre fils? Pourquoi t'installes-tu toujours ici?", lui disait-elle»). 
parar por separado las conductas de sus herederos, a los que va a visitar uno tras otro, y de constatar, como muchos de los padres que han aplicado el sistema de la "congra», que todos tratan de esquivar su parte de responsabilidad y de remitir cuanto antes al anciano a sus hermano$s($ as). Pero este régimen le permite al desgraciado padre crear una emulación entre sus herederos que, al suponer la existencia de ahorros inesperados, van a esforzarse por atraerle, cada uno a su casa respectiva, para quedar como único heredero del supuesto tesoro. En estos casos el propósito del anciano no consiste en recuperar una primacía doméstica perdida sino en conseguir las prestaciones y buenos tratamientos que suponía la donación: ya no se trata de jerarquía sino de reciprocidad.

Este tipo de organización narrativa del tema que nos ocupa se encuentra en versiones orientales ${ }^{89}$; se nota también que, en la leyenda del rey Lear y en las versiones que dependen de ella, el motivo de las visitas sucesivas que hace el anciano a sus hijas parece ser eco de un parecido sistema de hospedamiento alternativo.

Es probable que las versiones que presentan esta configuración correspondan más que otras a la forma primitiva del tipo: expresan con mayor coherencia la indigencia y dependencia del anciano, describen con más fuerza la competencia de los herederos en la ingratitud (al principio) y en la solicitud (después de la aplicación del ardid ideado por el padre o por su amigo) y dan más relieve a la conclusión al acrecentar la decepción de los ingratos, ya que, en sus estancias alternadas, el padre le había hecho creer, a cada uno de ellos por separado, que le iba a dejar la totalidad del supuesto tesoro. Además esta hipótesis se conforma con el probable entronque del cuento con la mitología del «Primer Rey», en la que son esenciales la dispersión de los herederos y la repartición del espacio (tierra o reino) en fragmentos distintos, siendo momento clave del relato el escrutinio separado de cada uno de sus hijos por el Soberano.

8) Al analizar y comparar las distintas versiones, escritas y orales, de un cuento aparentemente tan breve y sencillo, se nota por consiguiente toda una serie de estratificaciones subyacentes: el tipo narrativo del que depende es encrucijada de tradiciones folklóricas, principalmente orales; las variaciones en situaciones y argumentos corresponden, según

89) En un cuento indio (resumido por H. PARKER, op. cit., p. 242) la protagonista, maltratada por su nuera, va a vivir en casa de su hija: entonces el hijo regaña a su mujer por haber anulado su posibilidad de conseguir el supuesto tesoro y se esfuerza por traer de nuevo a su madre a su casa, donde la mima hasta su muerte. 
las versiones, a enfoques de diversos alcances y significados que sólo pueden comprenderse cuando se consideran en los contextos sociohistóricos en que nacieron y circularon dichạs versiones. La vigencia de un cuento de esta clase en la sociedad española aurisecular no es solamente una prueba más del arraigo medieval de su cultura: la comparación con versiones folklóricas todavía vivas en la tradición de algunas regiones de la península muestra que, aunque dominada por criterios ideológicos coherentes, principalmente aristocráticos y urbanos, esta sociedad sigue sensible, en sus representaciones, a unos desfases culturales característicos de ciertos sectores de la parte occidental del mundo indoeuropeo.

Estos desfases son la manifestación de una distorsión entre la «Ley» y su aplicación, ente el sistema de valores y los casos concretos que se presentan en la vida cotidiana: este cuento forma parte de una clase especial de «ficciones jurídicas», en las que se formulan al mismo tiempo (explícita o tácitamente) la norma y una casuística más o menos compleja - reflejando la diversidad de las versiones los múltiples tipos de aplicación e interpretación de la regla - a través de las cuales se proyectan y contrarrestan las distintas actitudes posibles cuando se trata de adaptar los principios a las situaciones individuales. En estos casos la flexibilidad de la tradición oral hace de ella el instrumento dialéctico privilegiado para contrastar los códigos abstractos y los modelos (y submodelos) de conducta.

En estos relatos se traslucen en fin los supuestos de una mentalidad «tradicional», todavía marcada por el pesimismo radical de la tradición «realista» medieval y por la ideología estamentista (cada casta en su sitio y cada grupo de edad en su puesto determinado en la jerarquía). Sin embargo, ya descuella la preocupación precapitalista por el buen funcionamiento de las sucesiones y por la buena gestión y transmisión del patrimonio: estas metas se consiguen a veces mediante artificios que se sitúan a medio camino entre los chantajes del usurero y las triquiñuelas y especulaciones mercantiles del bolsista o del jugador. Dichas tretas aparecen como un medio de soslayar los inconvenientes de un sistema familiar anacrónico, al que se considera como parcialmente inadaptado por estribar en un intercambio de prestaciones tradicionalmente determinadas y encauzadas que suponen una transparencia cultural inalterable, postulado utópico en un mundo social donde van triunfando la economía monetaria, la propiedad privada y el individualismo. Un mundo en el que, por lo tanto, se impone la desconfianza y se supone la consideración previa del propio interés, incluso en el contexto de la misma estirpe. Un mundo, en fin, donde se desarrolla el esquema urbano de la familia nuclear 
y se produce una atomización del clan extenso, así como una alteración del sentido tradicional de la convivencia solariega.

Nuestro cuento describe y satiriza unos efectos de esta mutación socio-antropológica, cuya consecuencia principal es un proceso de disgregación de la dimensión vertical del linaje: refleja el desconcierto producido por este proceso en las mentalidades. Plasmado acaso en el contexto de una campaña ideológica contra las dotes excesivas como factor de alteración del orden tradicional (por permitir, mediante el artificio del dinero y del casamiento, promociones sociales indebidas), influenciado probablemente, según los tiempos y las regiones, por los cambios y variaciones en las prácticas de sucesión, el cuento vuelve a movilizar arcaicas imágenes y las va reinterpretando, adaptadas a nuevos contextos.

A través de la ficción se nota cómo, en unas sociedades todavía marcadas por la disparidad de los sistemas de transmisión, por el desfase entre una sociabilidad familiar tradicional y los nuevos modelos de convivencia propios de la vida urbana, se remozan los términos de un debate prehistórico, hondamente enraizado en la memoria colectiva y en el folklore oral, relativo al sentido de la repartición del mundo, a las relaciones entre grupos de edad y a las continuidades genealógicas.

\author{
FRANÇOIS DELPECH \\ Centre National de la Recherche Scientifique \\ Paris
}

Se examinan varias versiones orales y literarias del tipo de cuento Aa-Th 982 (fingido tesoro que instiga a los hijos ingratos a mimar a su viejo padre) poniéndose de manifiesto sus conexiones folklóricas y su relación con el ciclo mítico indo-europeo relativo a las vicisitudes sufridas por el Primer Rey al repartir sus bienes y su reino entre sus hijos. El cuento forma parte de un conjunto de narraciones tradicionales de gran antigüedad y amplia difusión, centrado en el tema de la eliminación de los ancianos y contiene claras alusiones al motivo ritual del «martillo sagrado». Cobra actualidad y trascendencia social en una cultura posmedieval caracterizada por un desfase entre antiguas costumbres patrimoniales y nuevas tendencias individualistas al producirse una disgregación progresiva del linaje y de sus valores.

An analysis is made of some literary and oral versions of the tale-type Aa-Th 982 ( «Supposed chest of gold induces children to care for aged father»), emphasis being laid on its folklore connections and its relations with the indo-european mythical cycle concerning the ordeals suffered by the First King when he surrenders his 
kingdom and properties to his heirs. This folktale is part of a wide set of fictitious stories and cross-cultural traditions focussed on the eviction of old people, and it obviously refers to the celtic ritual motif of the «Holy Mawle». A new actuality and a stronger social meaning are confered to it in a post-medieval culture marked by a disruption of old patrimonial customs and a growing influence of individualism, coeval with the alteration of age old family structures and values. 